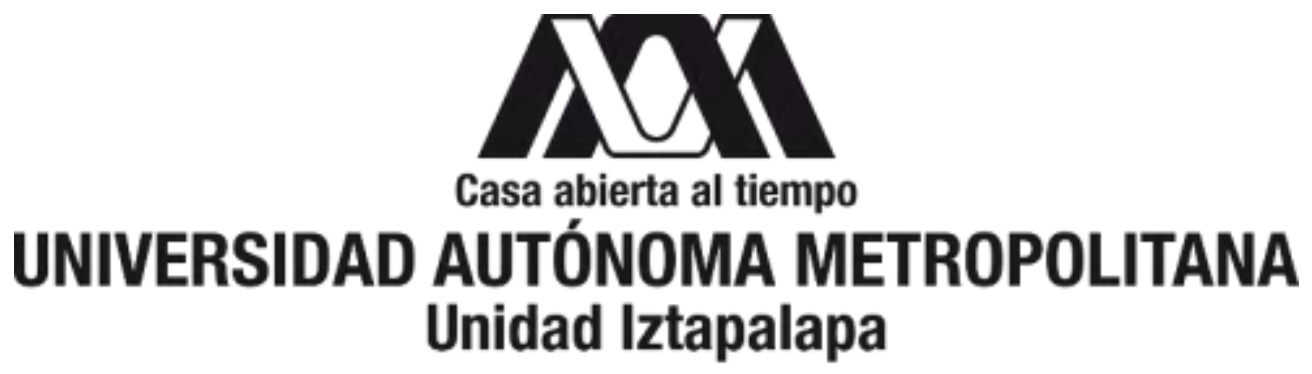

UNIVERSIDAD AUTÓNOMA METROPOLITANA

DIVISIÓN DE CIENCIAS BIOLÓGICAS Y DE LA SALUD

MAESTRÍA EN BIOLOGÍA DE LA REPRODUCCIÓN ANIMAL

\title{
ESTUDIO CIRCANUAL DE LOS CAMBIOS MORFOLÓGICOS Y FUNCIONALES DEL OVARIO Y LA ESPERMATECA DEL URODELO Ambystoma mexicanum
}

TES IS

Para obtener el grado de:

Maestro en Biología de la Reproducción Animal

Presenta:

BIOL. JOSÉ RODRIGO RIVERA LÓPEZ

COMITÉ TUTORAL

Director:

DR. MIGUEL ÁNGEL LEÓN GALVÁN

Asesores:

DRA. MARÍA DEL CARMEN URIBE ARANZÁBAL DR. MARIO GARCÍA LORENZANA

Ciudad de México, a 13 de febrero de 2020. 


\section{MIEMBROS DEL COMITÉ DE TUTORES}

Dr. Miguel Ángel León Galván.

Departamento de Biología.

División Académica de Ciencias Biológicas y de la Salud.

Universidad Autónoma Metropolitana--Iztapalapa.

Correo electrónico: leon@xanum.uam.mx

Dra. María del Carmen Uribe Aranzábal.

Departamento de Biología Comparada.

Facultad de Ciencias.

Universidad Nacional Autónoma de México.

Correo electrónico: mari3uribe3@gmail.com

Dr. Mario García Lorenzana.

Departamento de Biología de la Reproducción.

División Académica de Ciencias Biológicas y de la Salud.

Universidad Autónoma Metropolitana-Iztapalapa.

Correo electrónico: mglo@xanum.uam.mx 


\section{MIEMBROS DEL JURADO DE EXAMEN}

Dra. María del Carmen Uribe Aranzábal.

Departamento de Biología Comparada.

Facultad de Ciencias.

Universidad Nacional Autónoma de México.

Correo electrónico: mari3uribe3@gmail.com

\section{Dr. Mario García Lorenzana.}

Departamento de Biología de la Reproducción.

División Académica de Ciencias Biológicas y de la Salud.

Universidad Autónoma Metropolitana-Iztapalapa.

Correo electrónico: mglo@xanum.uam.mx

Dra. María del Rosario Tarragó Castellanos.

Departamento de Biología de la Reproducción.

División Académica de Ciencias Biológicas y de la Salud.

Universidad Autónoma Metropolitana-Iztapalapa.

Correo electrónico: mrtc@xanum.uam.mx

\section{Dra. Karla Pelz Serrano.}

Departamento de Ciencias Ambientales.

División Académica de Ciencias Biológicas y de la Salud.

Universidad Autónoma Metropolitana-Lerma.

Correo electrónico: k.pelz@correo.ler.uam.mx 


\section{AGRADECIMIENTOS}

Al Consejo Nacional de Ciencia y Tecnología (CONACYT) por haberme brindado el apoyo económico mediante la beca $\mathbf{8 6 8 8 9 2 / 6 3 7 7 1 5}$ que me permitió realizar mis estudios de posgrado y la realización de mi proyecto de tesis.

A la maestría en Biología de la Reproducción Animal de la Universidad Autónoma Metropolitana, Unidad Iztapalapa (UAM-I), registrada ante CONACYT con la clave 003797 por proporcionarme los conocimientos necesarios para desempeñarme en el área de la investigación y apoyarme con la culminación de este proyecto.

Al Centro de Investigaciones Biológicas y Acuícolas de Cuemanco (CIBAC) de la Universidad Autónoma Metropolitana, Unidad Xochimilco (UAM-X) a cargo del Dr. José Antonio Ocampo Cervantes y a su equipo de trabajo, entre ellos la Dra. Erika Servín Zamora y el Biol. Arturo Vergara Iglesias por proporcionarme los ejemplares y las instalaciones necesarias para poder realizar este proyecto.

Al Laboratorio de Biología de la Reproducción de la Facultad de Ciencias de la Universidad Nacional Autónoma de México a cargo de la Dra. María del Carmen Uribe Aranzábal y a su equipo de trabajo, el M. en C. Gabino de la Rosa Cruz y la M. en C. Adriana García Alarcón por permitirme el acceso a sus instalaciones para la realización de mi tesis y por los conocimientos y experiencias adquiridos durante mi estancia en el laboratorio.

A mi director de tesis, el Dr. Miguel Ángel León Galván, así como a mis asesores, la Dra. María del Carmen Uribe Aranzábal y al Dr. Mario García Lorenzana por todos los conocimientos y consejos que me han brindado durante todo este tiempo; muchas gracias. 


\section{JURADO DE EXAMEN}

Los miembros del jurado designado por la División de Ciencias Biológicas y de la Salud, Universidad Autónoma Metropolitana Iztapalapa, abajo firmantes, aprobaron la tesis titulada "Estudio circanual de los cambios morfológicos y funcionales del ovario y la espermateca del urodelo Ambystoma mexicanum" con fecha (fecha del examen oral)

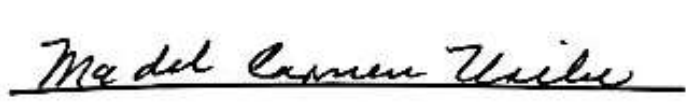
Dra. Maria del Carmen Uribe Aranzábal. Presidente.

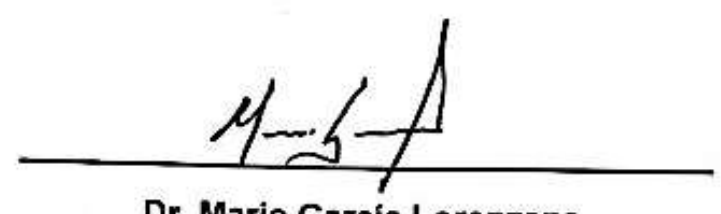

Dr. Mario Garcia Lorenzana.

Secretario.

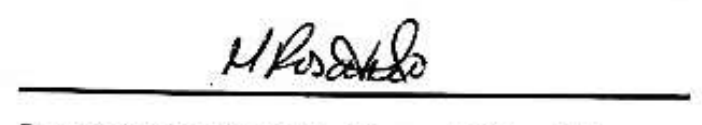

Dra. María del Rosario Tarragó Castellanos.

Vocal.

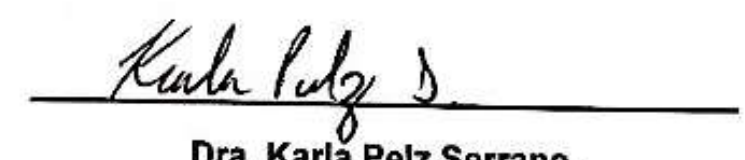

Dra. Karla Pelz Serrano.

Vocal. 


\section{DEDICATORIA}

Dedico este trabajo a varias personas que me apoyaron en diferentes formas.

A mis padres por creer en mí y apoyarme en esta travesía llamada vida. Gracias a ustedes es que estoy aquí y quien soy en parte se los debo a ustedes.

A mis amigos Jose N. A., Temo O. C., Sara M. C., Ary A. F., Chris O. N. y Fabi M. por escucharme y apoyarme en mis momentos más difíciles y emotivos. Gracias por alentarme a seguir adelante.

A mis compañeros de maestría: Sophie, Itzel, Moni, Sonia, Jahda, Jersain y Andrés por los buenos momentos que pasamos durante nuestra formación académica.

A la fuerza que mantiene al universo en balance y movimiento y que posiblemente, directa o indirectamente orquesto la serie de acontecimientos que me han traído hasta aquí.

Y por último, quizá a mí mismo, por seguir adelante. 


\section{CONTENIDO}

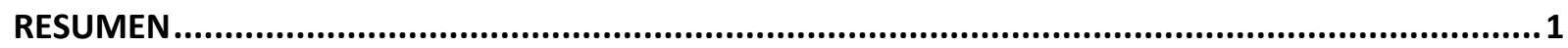

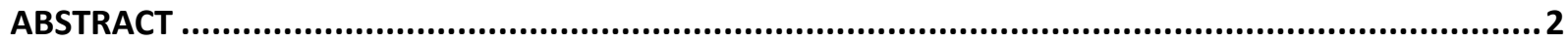

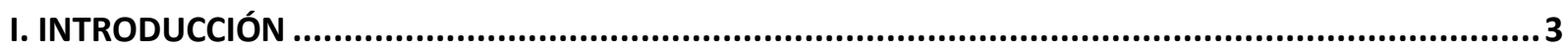

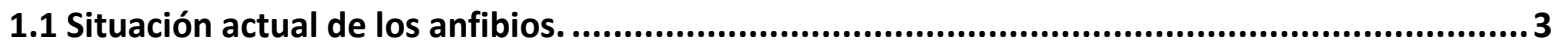

1.2 Ciclos reproductores y sistema reproductor femenino de Urodelos...................................4

1.3 Descripción y estatus de conservación de Ambystoma mexicanum ....................................7

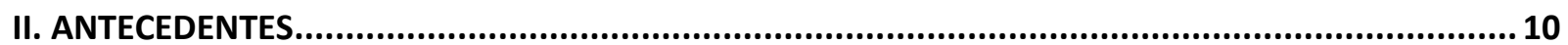

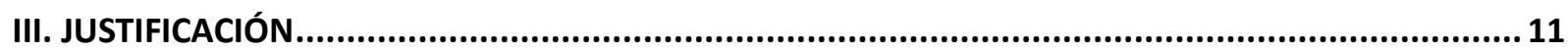

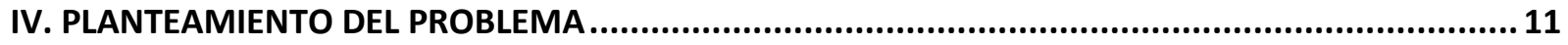

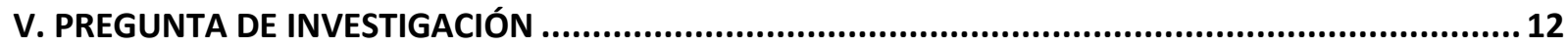

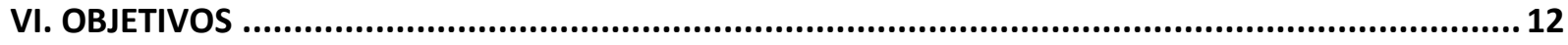

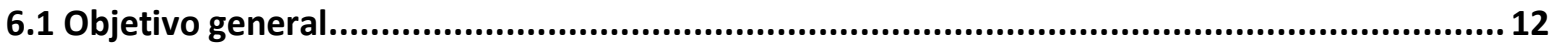

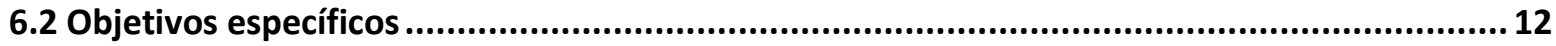

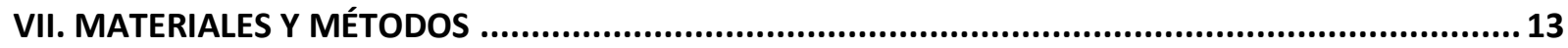

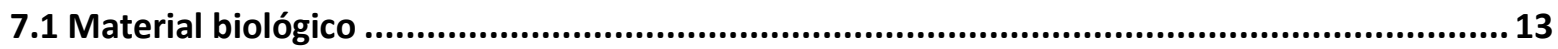

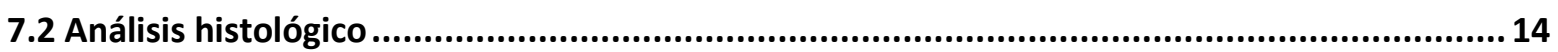

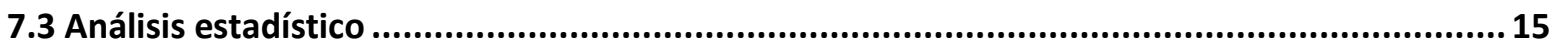

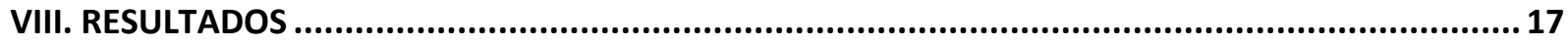

8.1 Características Morfológicas del Ovario ........................................................................ 17

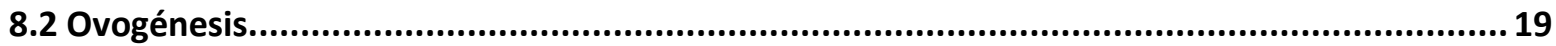

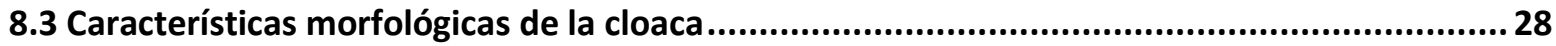

8.4 Variaciones estaciones del ciclo reproductor de Ambystoma mexicanum............................33

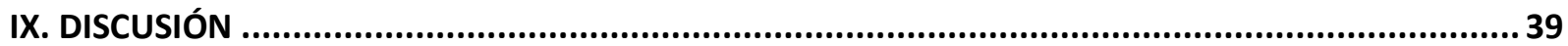

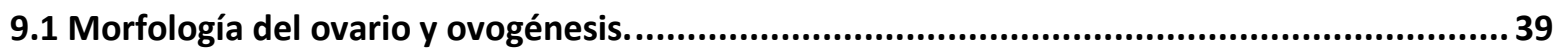

9.2 Morfología de la cloaca y las glándulas cloacales............................................................ 45

9.3 Cambios estacionales durante el ciclo anual...............................................................50

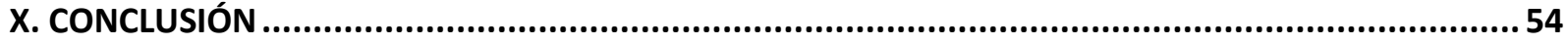

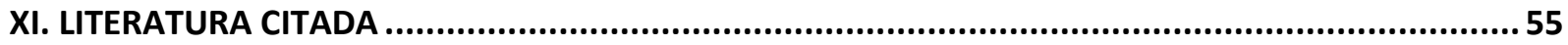




\section{RESUMEN}

El ajolote de Xochimilco (Ambystoma mexicanum) es una salamandra neoténica endémica de la zona lacustre del valle de México. Aunque es una especie que ha sido utilizada como un modelo biológico en diversos estudios ontogénicos y biomédicos, son escasos los conocimientos que se tienen acerca de su biología de la reproducción. Por lo tanto, el objetivo de este trabajo es describir las variaciones morfológicas del ovario y de la espermateca de $A$. mexicanum durante un ciclo anual con el fin de incrementar los conocimientos que se tienen acerca de su ciclo reproductor. Fueron utilizados 20 ejemplares en total. Las muestras de tejidos fueron procesadas utilizando la técnica histológica para microscopía de luz. Se realizaron cortes histológicos seriados de seis micrómetros y se utilizaron las siguientes técnicas de tinción: hematoxilina-eosina, tricrómica de Masson y tricrómica de Gallego para la descripción morfológica, ácido peryódico de Schiff para la identificación de carbohidratos neutros y azul alciano para la identificación de carbohidratos ácidos. Los ovarios de $A$. mexicanum son estructuras saculares donde se localiza el epitelio germinal, así como diferentes tipos de folículos. La cloaca de $A$. mexicanum presenta un epitelio columnar biestratificado con células ciliadas y secretoras. Se identificaron tres tipos de glándulas de morfología túbulo-alveolar: las ventrales, las dorsales y las espermatecas. Se observaron variaciones estacionales en las proporciones de los folículos ováricos durante el estudio, siendo el periodo de julio a enero donde se registró la mayor actividad ovárica. Por otro lado, no se observaron variaciones significativas en el diámetro de la espermateca o en la altura de su epitelio a lo largo de este estudio. 


\begin{abstract}
The Xochimilco axolotl (Ambystoma mexicanum) is a neothenic salamander endemic to the lacustrine zone of the Valley of Mexico. Although it is a species that has been used as a biological model in various ontogenetic and biomedical studies, there is scarce knowledge about its reproductive biology. Therefore, the objective of this work is to describe the morphological variations of the ovary and the spermatheca of $A$. mexicanum during an annual cycle, in order to increase the knowledge about its reproductive cycle. A total of 20 specimens were used. Tissue samples were processed using histological techniques for light microscopy. Serial histological sections of six micrometers were made and the following staining techniques were used: hematoxylineosin, Masson's trichrome and Gallego's trichrome for morphological description, periodic acid Schiff for the identification of neutral carbohydrates and alcian blue for the identification of acid carbohydrates. The ovaries of A. mexicanum are saccular structures where the germinal epithelium is located, as well as different types of follicles. The cloaca of $A$. mexicanum has a bistratified columnar epithelium with ciliated and secretory cells. Three types of tubule-alveolar morphology were identified: the ventral, the dorsal and the spermathecae. Seasonal variations were observed in the proportions of the ovarian follicles during the study, the period from July to January registered the highest ovarian activity. On the other hand, no significant variations were observed in the diameter of the spermatheca or in the height of its epithelium throughout this study.
\end{abstract}




\section{INTRODUCCIÓN}

\subsection{Situación actual de los anfibios.}

En los últimos 25 años el número de anfibios se ha reducido dramáticamente en diversos lugares del mundo y esta reducción se ha agravado a un ritmo alarmante, volviéndolos en la actualidad el taxón de vertebrados con la proporción más alta de especies en peligro de extinción (Beebee y Griffiths, 2005; Cushman, 2006). De acuerdo a Rawson et al. (2011), aproximadamente un tercio de las 6,284 especies de anfibios están en peligro de extinción y un $43 \%$ se enfrenta a una disminución de sus poblaciones. El declive se puede deber a una compleja interacción de factores como son: cambio climático, su alta vulnerabilidad a los patógenos, introducción de especies exóticas, exposición a la creciente radiación ultravioleta, contaminación, explotación directa de estas especies, así como a la fragmentación, degradación y pérdida del hábitat original por las actividades antropológicas (Beebee y Griffiths, 2005; Cushman, 2006; Barrett y Guyer, 2008; Harmer y Mcdonnell, 2008; Rawson et al., 2011).

Debido a ello, se están adecuando diferentes tecnologías reproductoras con el fin de mejorar los planes de manejo y conservación de las especies de anfibios (Kouba et al., 2009; Browne et al., 2011; Rawson et al., 2011 y Kouba et al., 2013). Entre estas especies están: Rana sylvatica (Beesley et al., 1998), Rhinella marina (Browne et al., 1998; Proaño-Olmos, 2013), Crinia signífera, Limnodynastes peroni, Litoria brevipelmata, L. dentata, L. fallax, L. latopalmata, L. lesueuri, L. nasuta, L. peroni, L. phyllochroa, L. subglandulosa, Philoria sp., Pseudophryne bibroni (Browne et al., 2002) y Rana temporaria (Shishova et al., 2011). La mayoría de estos trabajos se han enfocado en Anuros. 


\subsection{Ciclos reproductores y sistema reproductor femenino de Urodelos}

Los estudios comparados sobre la biología de la reproducción han demostrado que existe una gran variabilidad de patrones reproductores entre las diversas especies de vertebrados (Roldan y Garde, 2004). De acuerdo a Ferreira et al. (2009), los ciclos reproductores pueden clasificarse en tres tipos: 1) Continuos, sin variaciones en la actividad reproductora, 2) Continuos pero con variaciones en la actividad reproductora, donde, en determinadas temporadas hay una mayor producción de gametos que en otras, y 3) Estacional, donde se observan periodos de inactividad reproductora.

En urodelos, al igual que en otros vertebrados estacionales, se presentan variaciones morfológicas y fisiológicas del aparato reproductor, observándose cambios cíclicos relacionados a las condiciones climáticas del ambiente, tales como la duración del fotoperiodo, la temperatura y la precipitación pluvial (Baitchman y Herman, 2014; Yartsev y Kuranova, 2015). Un adecuado aporte de nutrientes también es un factor esencial en los procesos reproductores, particularmente en las hembras donde la vitelogénesis y la maduración de los ovocitos requieren abundantes reservas de energía (Uribe, 2009).

De acuerdo con Uribe (2009) el sistema reproductor femenino de la mayoría de los urodelos consiste de dos ovarios, dos oviductos y la espermateca. Los ovarios de los urodelos son estructuras elongadas e irregulares localizadas en la cavidad abdominal y sujetas a la pared dorsal por el mesovario. A nivel histológico, el ovario es una estructura sacular con varios sacos ováricos y una cavidad central llena de linfa. La pared del ovario se encuentra delimitada por epitelio cúbico simple, el cual rodea a la corteza ovárica, la cual se compone de epitelio germinal y estroma adyacente. El epitelio germinal consiste de células germinales (ovogonias y ovocitos) y células somáticas (algunas de ellas formarán células de la granulosa) apoyadas por una membrana basal. El estroma ovárico está conformado por tejido conjuntivo laxo que contiene fibras de colágena, fibroblastos, varios tipos de células del sistema inmunológico, vasos sanguíneos, vasos linfáticos y fibras nerviosas (Uribe, 2003; 2009). 
La ovogénesis es un proceso complejo por el cual una célula progenitora, la ovogonia atraviesa por varios procesos celulares cómo la mitosis, meiosis, síntesis de ARN y acumulación de sustancias de reserva para convertirse en un ovocito maduro (Uribe, 2003). De acuerdo a Grier, Uribe y Patiño (2009) la ovogénesis comprende cinco estadios: proliferación de ovogonias, cromatina-nucleolo, crecimiento primario o previtelogénesis, crecimiento secundario o vitelogénesis y ovulación.

Los oviductos son órganos pares elongados que se extienden a cada lado de la línea media de la cavidad corporal, sujetos a la pared dorsal por el mesenterio dorsal. Estos conductos se dividen en cuatro regiones que son morfológica y funcionalmente diferentes: el infundíbulo u ostium, la pars recta o atrium, la pars convoluta o ampolla y el ovisaco o parte aglandular posterior (Greven, 2002; Uribe, 2009).

A. El infundíbulo está formado por una delgada pared que posee una mucosa muy plegada. Los pliegues de la mucosa son de forma y tamaño irregular y están proyectados hacia el lumen. La mucosa en el infundíbulo está constituida por un epitelio cúbico o columnar con células ciliadas y secretoras.

B. La pars recta es una región de transición entre el infundíbulo aglandular y la ampolla altamente glandular. Su pared está plegada al igual que la del infundíbulo, pero los pliegues son más cortos y gruesos y el epitelio muestra algunas células secretoras, encontrándose solas o en grupos y dispersas entre las células epiteliales cúbicas.

C. La pars convoluta, llamada también ampolla o región contorneada glandular media, muestra un progresivo aumento en el número de glándulas tubulares. El epitelio luminal contiene pocas células ciliadas dispersas entre numerosas células secretoras. Las células secretoras son grandes, de forma prismática, tienen un núcleo basal y el citoplasma es ligeramente vacuolado. De acuerdo con Greven (2002), estas glándulas se abren al lumen secretando proteínas glicosiladas, mucopolisacáridos ácidos y neutros, mucopolisacáridos sulfatados y carbohidratos neutros, los cuales se van 
acumulando alrededor del ovocito, conformando las subcapas que componen la cubierta gelatinosa.

D. El ovisaco es la región más caudal del oviducto, el cual forma una región aglandular corta y recta. La mucosa presenta epitelio columnar con células ciliadas. En contraste con otras regiones del oviducto, las capas de tejido conjuntivo y muscular del ovisaco son más gruesas. El incremento en el número de fibras musculares en esta región sirve de apoyo durante la oviposición.

La espermateca es una estructura glandular que se localiza dorso-lateralmente en el lumen cloacal y participa en el almacenamiento de los espermatozoides, estando presente en muchas especies de salamandras (Uribe, 2009) (Cuadro 1). Hay dos tipos de espermateca: 1) simple, constituida por numerosas glándulas tubulares simples y 2) compuesta, constituida por una sola glándula alveolar compuesta (González-León y Ramírez-Pinilla, 2011). La espermateca no se considera parte del oviducto ya que es un derivado de la cloaca. Una vez que el espermatóforo está en el interior de la cloaca de las hembras, éste degenera liberando a los espermatozoides, los cuales migran a lo largo de la pared dorsal de la cloaca hacia la espermateca, manteniéndose almacenados y en quiescencia. Una vez inseminada, la hembra puede esperar hasta que se presenten las condiciones adecuadas para la ovulación. Los espermatozoides pueden ser mantenidos en la espermateca durante largos periodos de tiempo, desde unas pocas horas hasta meses o incluso años (Sever, 1991, 1995).

Por ello, es de gran importancia realizar estudios sobre la biología reproductora de especies silvestres, como es el caso de Ambystoma mexicanum, con el propósito de obtener y utilizar la información resultante en el desarrollo de protocolos de conservación (Roldán y Garde 2004; Kuoba et al., 2009); un tema de especial interés para un país megadiverso, como es el caso de México, el cual ocupa el quinto lugar en riqueza de anfibios (Parra-Olea, Flores-Villela y Mendoza-Almeralla, 2014), no obstante, se desconocen aspectos básicos de la biología reproductora de estas especies. 


\subsection{Descripción y estatus de conservación de Ambystoma mexicanum}

El ajolote de Xochimilco (Ambystoma mexicanum) es una salamandra de la familia Ambystomatidae de distribución restringida, encontrándose solamente en dos cuerpos de agua localizados en el Valle de México: el lago de Xochimilco y el lago de Chalco, los cuales se han visto perturbados por la actividad humana (ZambranoGonzález et al., 2003). A. mexicanum muestra un estado neoténico, es decir, no presentan metamorfosis, permaneciendo en su forma acuática larval a lo largo de todo su ciclo de vida. Presenta una longitud hocico-cloaca promedio de $132 \mathrm{~mm}$ con una cola de $125 \mathrm{~mm}$ de longitud, y la aleta caudal detrás de la intersección de las branquias. Es un organismo robusto de piel lisa en la mayoría del cuerpo, puede presentar glándulas con poros en la cabeza. Son de color oscuro entre negro y café aunque el vientre y la región del saco gular muestran una coloración amarillenta o parda con puntos oscuros y algunas veces manchas claras (Aguilar-Miguel y Casas-Andreu, 2005). Las características dimórficas sexuales solo son visibles en la época de reproducción, ya que se observa una dilatación en la zona cloacal de los machos, producto del incremento de tamaño de las glándulas cloacales (Servín-Zamora, 2011). De acuerdo con Park et al. (2004), no se tienen datos concisos sobre el inicio y la duración de la temporada reproductora de $A$. mexicanum y los registros que se tienen varían de manera considerable unos de otros.

Debido a factores como la contaminación ambiental, la presión de especies introducidas y la sobreexplotación humana para diferentes fines (alimenticio y de ornato), la población de $A$. mexicanum ha sido mermada drásticamente, por lo que la Unión Internacional para la Conservación de la Naturaleza (IUCN) en 2006 colocó a esta especie en la categoría de "en peligro crítico" (Zambrano et al., 2010) y la Norma Oficial Mexicana 059 de SEMARNAT (NOM-059-SEMARNAT-2010) la catalogó como especie en peligro de extinción.

La mejor estrategia para la conservación de la biodiversidad es la preservación del medio natural, sin embargo, en algunas ocasiones, como es el caso del lago de Xochimilco, no es una estrategia posible; por estos motivos es importante reconocer 
que existen estrategias complementarias para la conservación de la biodiversidad. Entre ellas se incluyen la cría en cautividad, el desarrollo de bancos de recursos genéticos y el uso de biotecnologías para su reproducción (Holt et al., 2003; Howard et al., 2003; Roldan y Garde, 2004; Kouba et al., 2009). La cría en cautiverio permite el conocimiento sobre su reproducción, que no es de fácil acceso cuando los animales están libres en la naturaleza (Temple-Smith, 2003).

Con respecto a A. mexicanum, Servín-Zamora (2011) enlista algunas instituciones, nacionales y extranjeras, donde actualmente se han establecido colonias reproductoras, entre ellas:

Nacionales:

- El Zoológico de Chapultepec

- El Zoológico Los Coyotes

- El Centro de Investigaciones Biológicas y Acuícolas de Cuemanco (CIBAC)

- La Facultad de Estudios Superiores (FES) Unidad Iztacala

- El Instituto de Biología de la UNAM

- La UMA Umbral Axochiatl de Xochimilco

Extranjeras:

- Universidad de Indiana, EUA

- Universidad de Washington, EUA

- El Zoológico de Toronto, Canadá

- El Zoológico de Chester, Reino Unido

- El Zoológico de Beijing, China.

Sin embargo, no hay un plan de reproducción asistida para esta especie en estas instituciones. Por lo tanto, es fundamental estudiar las características de sus sistemas reproductores, cómo es el caso del análisis histológico del ovario y la espermateca durante un ciclo anual. El análisis histológico del ovario es esencial, ya que ofrece datos sobre la actividad gametogénica y de las etapas del ciclo reproductor. Además, 
el análisis histológico de la espermateca permitirá definir la naturaleza de sus secreciones y sus variaciones durante la época reproductora, lo que permitirá comprender los procesos por los que pasan los espermatozoides y así, aportar conocimientos que se incorporen a los programas de conservación tanto para esta especie como para otras relacionadas a diferentes escalas (conservación de germoplasma, reproducción in situ, reproducción ex situ, reproducción asistida).

\begin{tabular}{|c|c|c|c|}
\hline Especie & $\begin{array}{c}\text { Tipo de } \\
\text { espermateca }\end{array}$ & $\begin{array}{c}\text { Morfología del } \\
\text { epitelio }\end{array}$ & Secreciones \\
\hline $\begin{array}{c}\text { Eurycea cirrigera } \\
\text { (Sever, 1991, Sever y } \\
\text { Brunette, 1993) }\end{array}$ & Compuesta & Cilíndrico & $\begin{array}{c}\text { Polisacáridos neutros y } \\
\text { proteínas (PAS+). }\end{array}$ \\
\hline $\begin{array}{c}\text { Ambystoma opacum } \\
\text { (Sever y Kloepeer, 1993) }\end{array}$ & Simple & $\begin{array}{l}\text { Plano, } \\
\text { Columnar }\end{array}$ & $\begin{array}{c}\text { Mucopolisacáridos ácidos } \\
\text { (AA+) Lípidos (Sudan } \\
\text { negro +) }\end{array}$ \\
\hline $\begin{array}{l}\text { Salamandra terdigitata } \\
\text { (Brizzi, Delfino y Calloni, } \\
\text { 1989; Brizzi, Delfino, Selmi, } \\
\text { \& Sever, 1995) }\end{array}$ & Simple & $\begin{array}{l}\text { Cúbico, } \\
\text { Cilíndrico }\end{array}$ & $\begin{array}{c}\text { Mucopolisacáridos } \\
\text { ácidos, glúcidos y } \\
\text { proteínas (AA+, PAS+, } \\
\text { Ninhidrina/Schiff +) }\end{array}$ \\
\hline $\begin{array}{c}\text { Ambystoma tigrinum } \\
\text { (Sever, 1995) }\end{array}$ & Simple & Columnar & $\begin{array}{l}\text { Glicoproteínas } \\
\qquad(\text { PAS +) }\end{array}$ \\
\hline $\begin{array}{c}\text { Notophthalmus viridescens } \\
\text { (Sever, Rania, y Krenz, } \\
\text { 1996) }\end{array}$ & Simple & $\begin{array}{l}\text { Cúbico o } \\
\text { Columnar }\end{array}$ & $\begin{array}{l}\text { Glicoproteínas } \\
\qquad(\text { PAS +) }\end{array}$ \\
\hline $\begin{array}{c}\text { Triturus vulgaris } \\
\text { (Sever et al., 1999) }\end{array}$ & Simple & Cúbico & $\begin{array}{l}\text { Carbohidratos neutros } \\
\qquad(\text { PAS }+)\end{array}$ \\
\hline $\begin{array}{c}\text { Rhyacotriton variagatus } \\
\text { (Sever, Tait, Diller, y } \\
\text { Burkholder, 2004) }\end{array}$ & Simple & $\begin{array}{l}\text { Cúbico a } \\
\text { Columnar }\end{array}$ & $\begin{array}{c}\text { Mucopolisacáridos ácidos } \\
\text { y Carbohidratos neutros } \\
\text { (AA+ y PAS+) }\end{array}$ \\
\hline $\begin{array}{c}\text { Bolitoglossa nicefori } \\
\text { (González-León y Ramírez- } \\
\text { Pinilla, 2011) }\end{array}$ & Compuesta & Columnar & $\begin{array}{c}\text { Mucopolisacáridos ácidos } \\
\text { y Carbohidratos neutros } \\
\text { (AA+ PAS+) }\end{array}$ \\
\hline
\end{tabular}

Cuadro 1. Estudios histoquímicos de las espermatecas de diferentes especies. 


\section{ANTECEDENTES}

Los estudios realizados en $A$. mexicanum se han enfocado mayormente a su ontogenia y capacidad regenerativa (Schreckenberg y Jacobson, 1975; Tank et al., 1976; Endo et al., 2004; Satoh et al., 2008) y recientemente, a cuestiones poblacionales y ecológicas (Zambrano et al., 2010). En cuanto a su reproducción, no se conoce claramente el periodo de su actividad sexual y los diferentes reportes existentes aportan información que varía de manera considerable. Al respecto, Park et al. (2004), sugieren que puede ser en los meses de primavera, mientras que ServínZamora (2011) indica que la época de reproducción tiene lugar de diciembre a junio, aunque también menciona, con base en lo relatado por pescadores y criadores de Xochimilco, que la reproducción puede ser de noviembre a abril. La Comisión Nacional para el Conocimiento y Uso de la Biodiversidad (CONABIO, 2011) reporta que el periodo reproductivo de $A$. mexicanum abarca de noviembre a febrero.

Entre los pocos estudios relacionados con la biología reproductora de $A$. mexicanum, se encuentran los trabajos de Uribe et al., (1989) con la descripción histológica del oviducto, de Carroll et al. (1992) con un análisis estructural de la composición macromolecular de la cubierta gelatinosa de los huevos, de Mansour et al. (2011) quienes estandarizaron el protocolo para la obtención de gametos masculinos y femeninos y de Mendoza-Cruz et al. (2017), con una descripción morfogenética del desarrollo de las gónadas y la diferenciación sexual en los estadios embrionarios y larvales.

En relación a la espermateca, en el cuadro 1 se enlistan los trabajos histoquímicos que se han realizado en diferentes especies de urodelos. 


\section{JUSTIFICACIÓN}

El urodelo $A$. mexicanum y el resto de las especies con las que cohabita son elementos importantes dentro de la red trófica, así como en la dinámica del ecosistema al cual pertenece. Desde el punto de vista biomédico es una especie transcendental que se ha convertido en un modelo biológico de gran valor en el campo de la regeneración tisular. Además, es una especie neoténica y endémica del altiplano central mexicano. Sin embargo, la información que se tiene respecto a su reproducción es realmente limitada. Actualmente, varias instituciones nacionales e internacionales han establecido colonias de $A$. mexicanum pero simplemente se han limitado a recrear las condiciones óptimas para el apareamiento de los ejemplares o al uso de técnicas como la maceración de las gónadas para la obtención de gametos; en este último caso se han presentado tasas de fecundidad bajas. Debido a que $A$. mexicanum es una especie que presenta fecundación interna, es imperante conocer la dinámica de los procesos morfofisiológicos asociados a su reproducción. Por ello, para lograr un plan de manejo adecuado, es de vital importancia conocer la información básica sobre su reproducción, como la duración del ciclo reproductor y en especial, la espermateca, que puede servir como base y punto de partida para el desarrollo y la optimización de diversas tecnologías que sean aplicadas en planes de conservación a diferentes escalas que contribuyan al éxito de su reproducción.

\section{PLANTEAMIENTO DEL PROBLEMA}

Una problemática que limita el manejo de la reproducción de $A$. mexicanum en cautiverio, es el hecho de que presenta fecundación interna, lo que dificulta reconocer la dinámica involucrada en el proceso de la fertilización. Por ello, se requiere del estudio del ovario como órgano indicador de la actividad reproductora que regula la actividad de los otros componentes del aparato reproductor, como la espermateca, una glándula que participa con el almacenamiento de los espermatozoides. 


\section{PREGUNTA DE INVESTIGACIÓN}

¿Cuáles son los cambios morfofuncionales que se presentan en el ovario y en la espermateca de $A$. mexicanum a lo largo de un ciclo reproductor?

\section{OBJETIVOS}

\subsection{Objetivo general}

Describir las variaciones morfológicas y funcionales presentes en el ovario y en la espermateca de A. mexicanum durante un ciclo anual.

\subsection{Objetivos específicos}

Describir las características histológicas del ovario y de la cloaca de $A$. mexicanum.

Definir el ciclo reproductor anual de acuerdo a los cambios morfológicos del ovario y los estadios de la ovogénesis.

Describir las variaciones morfológicas de la espermateca en las diferentes estaciones del ciclo anual. 


\section{MATERIALES Y MÉTODOS}

\subsection{Material biológico}

Se utilizaron 20 hembras y 10 machos adultos, los cuales fueron proporcionados por el Centro de Investigaciones Biológicas y Acuícolas de Cuemanco (CIBAC), apegándose a lo estipulado en la NOM-059-SEMARNAT-2010 para especies nacionales en categoría de riesgo, ya que, al tomarse los ejemplares de una colonia en condiciones de cautiverio, no se ven afectadas las poblaciones silvestres. Todos los ejemplares fueron previamente seleccionados con respecto a las descripciones sobre la talla de los adultos y sexados de acuerdo a la morfología cloacal, siguiendo las indicaciones de Aguilar-Miguel y Casas-Andreu (2005) y Mena-González y ServínZamora (2015). Las colectas se realizaron en los meses de julio, octubre, enero y abril. Se colectaron de tres y cuatro hembras en cada mes (julio: cuatro ejemplares, con una repetición de tres ejemplares; octubre: cuatro ejemplares; abril: 3 ejemplares). Debido a que los reportes que se tienen del periodo reproductor de $A$. mexicanum señalan al mes de enero como el pico de la actividad reproductora, se destinó un mayor número de ejemplares (seis ejemplares) para este mes y se realizaron algunas actividades como la regulación de horas luz (cinco horas luz) y el descenso de la temperatura para inducir el apareamiento y la fecundación; esto con el fin de conocer la dinámica del ovario y la espermateca durante este proceso. Para ello se colocaron los ejemplares en una pecera de una capacidad promedio de $1.505 \mathrm{~m}^{3}$ a temperatura constante de $13^{\circ} \mathrm{C}$, la cual estaba dividida en tres secciones. En cada sección fueron colocados los ejemplares en una proporción 1:2 entre hembras y machos respectivamente, por un lapso de tres días. Cada 24 horas se revisó el lecho de la pecera en búsqueda de espermatóforos. Una vez localizados, se esperó a que las hembras los colectaran y se prosiguió a retirar a los machos.

Con respecto a la toma de muestras durante este periodo, se siguió la siguiente dinámica relacionada con el momento en que fueron colectados los espermatóforos. Cuando la primera hembra colectó los espermatóforos de su sección, se tomaron las muestras inmediatamente. En el caso de las hembras restantes, se dio un lapso de 
tres días entre cada una de ellas para realizar la colecta de tejidos, es decir, cuando se observó que la segunda hembra había colectado los espermatóforos, se dio un lapso de tres días a partir de ese momento antes de la toma de muestras. Para la tercera hembra fueron 6 días, para la cuarta 9 días y para la quinta 12 días, esto con el fin conocer el tiempo promedio de almacenamiento espermático en $A$. mexicanum. A la par de la primera hembra, se disecó otra que no estaba sometida ni a las condiciones de la pecera ni a la presencia de los machos, esto con el fin de comparar las variaciones morfológicas entre un ejemplar a temperatura ambiente y aislada de los machos con el resto de los ejemplares que si estaban sometidos a los factores antes mencionados.

\subsection{Análisis histológico}

Las hembras de $A$. mexicanum fueron anestesiadas con eugenol y sacrificadas con pentobarbital sódico. Se extrajeron los ovarios y la región cloacal, los cuales se fijaron con solución Bouin Dubosq por 24 horas y se sometieron al procesamiento histológico. Para lo cual, los tejidos fueron deshidratados en diferentes concentraciones de alcohol etílico, aclarados en xileno, embebidos en parafina (paraplast plus, McComick®) y se realizaron cortes seriados de $6 \mu \mathrm{m}$ en un micrótomo. Se utilizaron las técnicas de tinción de Hematoxilina y Eosina (H-E), Tricrómica de Gallego (T-Gall) y Tricrómica de Masson (T-Mass) (Luna, 1973; Humason, 1979). Para la descripción morfológica general y para el estudio histoquímico se incluyeron las siguientes técnicas: ácido peryódico de Schiff (PAS) para carbohidratos neutros como glucoproteínas y azul alciano (A.A.) ( $\mathrm{pH}$ 2.5) para carbohidratos ácidos como algunos mucopolisacáridos sulfatados, de acuerdo a la metodología utilizada por Sever y Kloepfer (1993), Sever (1995) y González-León y Ramírez-Pinilla (2011) para identificar la composición química de las secreciones en la espermateca (Cuadro 1). Para la determinación de las variaciones del ovario se utilizaron los siguientes criterios: el tamaño de los ovocitos, las características del núcleo y el citoplasma y la morfología de las células foliculares y la zona pelúcida. Para ello se utilizó una adecuación de un sistema de clasificación propuesto por Grier et al (2009) (Cuadro 2). Para el caso de 
la espermateca, se analizaron la morfología del epitelio y la composición química de sus secreciones a lo largo del ciclo anual. La captura de imágenes se realizó con una cámara digital Olympus C-5050ZOOM, acoplada a un microscopio Olympus CX31.

\subsection{Análisis estadístico}

Adicional a la descripción histológica del ovario y de la espermateca, se tomó la longitud de los ovarios durante cada muestreo y se realizó un conteo de los diferentes tipos de folículos ováricos $(\mathrm{N}=40)$ presentes en cada estación. Para la espermateca se registró el diámetro de la misma $(N=10)$ así como la altura de su epitelio $(N=10)$ también durante cada estación. Las medidas morfométricas se realizaron con el programa de análisis de imagen AxioVision SE64 Rel. 4.9.1.

Para el análisis estadístico, se utilizaron los datos antes mencionados con el fin de conocer el estadio reproductor de los ejemplares. Estos fueron sometidos a una prueba de normalidad de Kolmogórov-Smirnov y posteriormente se realizó un análisis de varianza (ANOVA) para comparar la varianza entre las diferentes estaciones de estudio. El análisis estadístico se realizó con el programa STATGRAPHICS Centurión $\mathrm{XVI} . \mathrm{I}$. 
Cuadro 2. Modificación de la clasificación propuesta por Grier, Uribe y Patiño (2009) para los estadios de la ovogénesis.

\begin{tabular}{|c|c|c|c|}
\hline CODIGOS & ETAPAS & ESTADIOS & PERIODOS \\
\hline OP & $\begin{array}{c}\text { Formación de } \\
\text { nidos germinales }\end{array}$ & $\begin{array}{c}\text { Proliferación de } \\
\text { ovogonias }\end{array}$ & \multirow{5}{*}{ Meiosis I } \\
\hline $\mathrm{CNI}$ & Leptoteno & \multirow{4}{*}{$\begin{array}{l}\text { Cromatina- } \\
\text { nucléolo }\end{array}$} & \\
\hline $\mathrm{CNz}$ & Zigoteno & & \\
\hline $\mathrm{CNp}$ & Paquiteno & & \\
\hline CNed & $\begin{array}{l}\text { Diploteno } \\
\text { temprano }\end{array}$ & & \\
\hline PV-I & Previtelogénesis I & \multirow{2}{*}{$\begin{array}{c}\text { Crecimiento } \\
\text { primario o } \\
\text { Previtelogénesis }\end{array}$} & \multirow{4}{*}{$\begin{array}{c}\text { Primer arresto } \\
\text { meiótico }\end{array}$} \\
\hline PV-II & Previtelogénesis II & & \\
\hline V-III & $\begin{array}{c}\text { Crecimiento } \\
\text { secundario } \\
\text { temprano o } \\
\text { Vitelogénesis III }\end{array}$ & \multirow{3}{*}{$\begin{array}{l}\text { Crecimiento } \\
\text { secundario o } \\
\text { vitelogénesis. }\end{array}$} & \\
\hline V-IV & $\begin{array}{c}\text { Crecimiento } \\
\text { secundario medio } \\
\text { o Vitelogénesis IV }\end{array}$ & & \\
\hline V-V & $\begin{array}{c}\text { Crecimiento } \\
\text { secundario tardío o } \\
\text { Vitelogénesis V }\end{array}$ & & Meiosis II \\
\hline OV & $\begin{array}{c}\text { Ovocito } \\
\text { preovulatorio. }\end{array}$ & Ovulación. & $\begin{array}{c}\text { Segundo arresto } \\
\text { meiótico. }\end{array}$ \\
\hline
\end{tabular}




\section{RESULTADOS}

\subsection{Características Morfológicas del Ovario}

Los ovarios de $A$. mexicanum son dos estructuras alargadas de forma irregular que se localizan en la región media posterior del cuerpo, siendo sujetas a la pared dorsal de la cavidad celómica por el mesovario y en paralelo a los oviductos. El tamaño de los ovarios varía en relación a la época reproductora, ya que en algunos periodos del año, los ovarios ocupan gran parte de la cavidad celómica (Fig. 1). A nivel histológico (Fig. 2A), el ovario es una estructura sacular conformada por varios sacos ováricos, los cuales presentan una cavidad central llena de linfa. Rodeando esta cavidad se encuentra el epitelio germinal (Fig. 2B y $3 \mathrm{~A}$ ). Este último está formado por células germinales, ovogonias y ovocitos en etapas de meiosis, y células somáticas, también denominadas células prefoliculares, las cuales pueden presentar una morfología cúbica o plana. Subyacente al epitelio germinal se encuentra el estroma ovárico, el cual está constituido por tejido conjuntivo laxo vascularizado y donde se pueden observar folículos ováricos en diferentes grados de desarrollo (Fig. 2B y 2C), folículos atrésicos (Fig. 2E) y folículos postovulatorios o cuerpos lúteos (Fig. 2D).

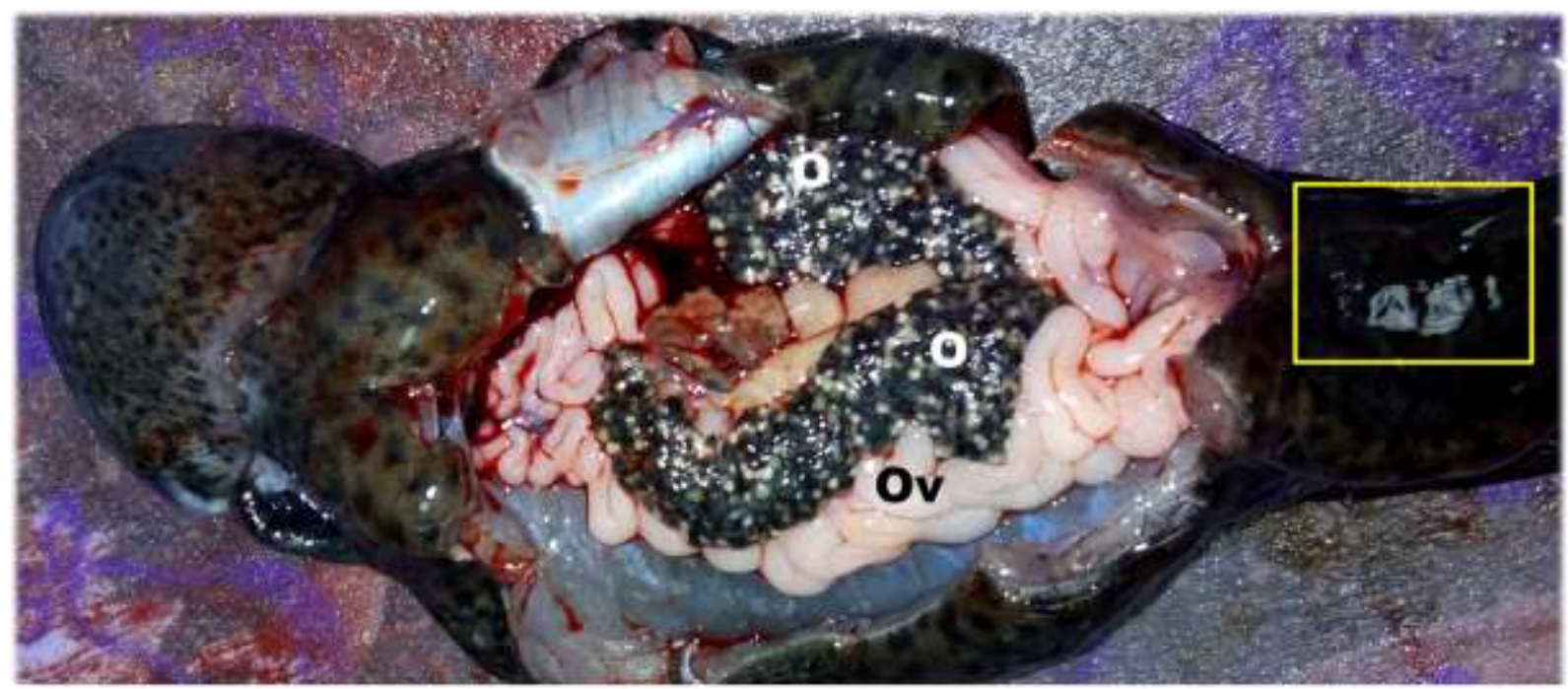

Figura 1. Vista macroscópica del sistema reproductor femenino de $A$. mexicanum. Ovario $(O)$, Oviducto (Ov), Orificio cloacal (recuadro). 

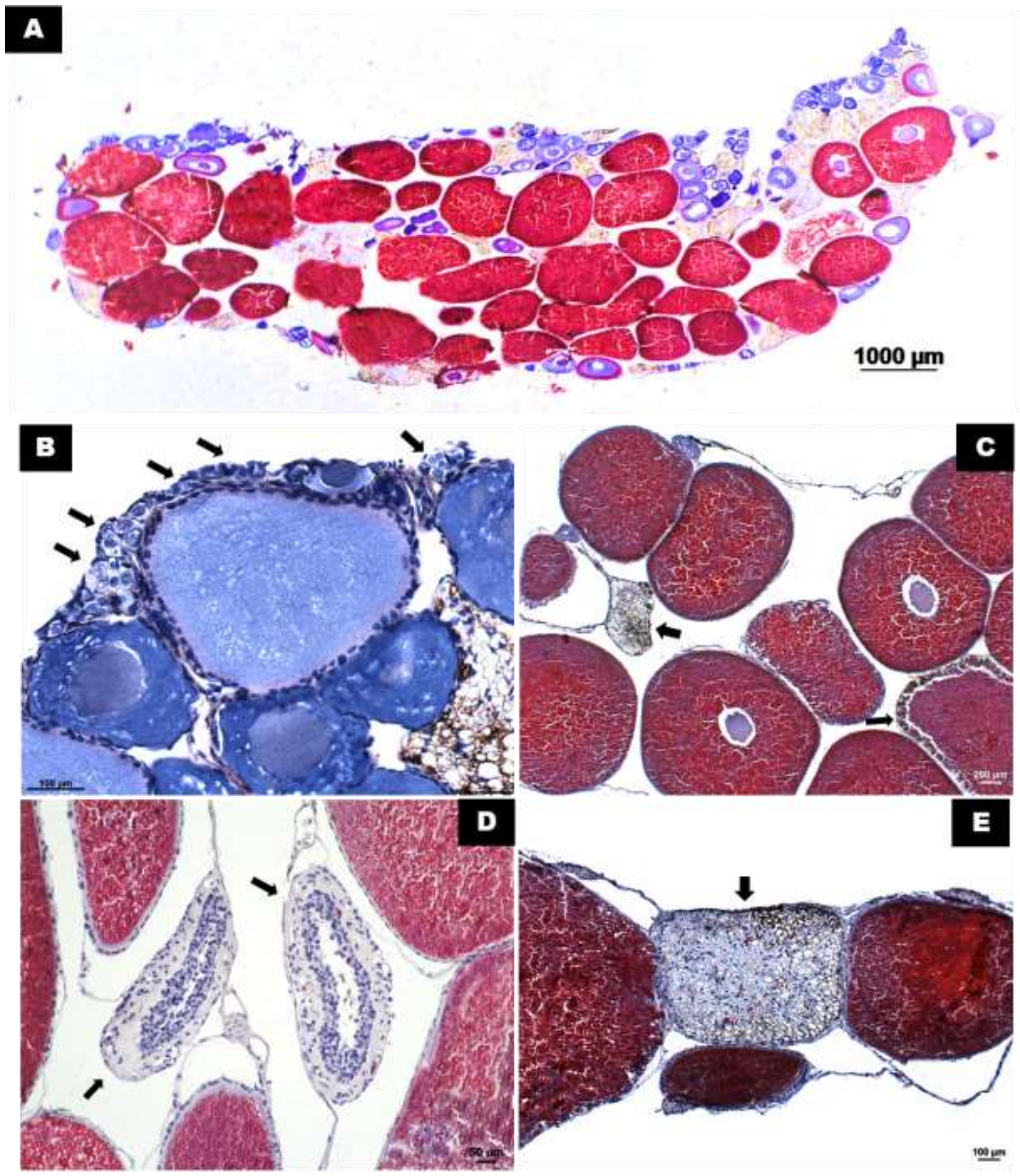

Figura 2. Componentes del ovario de A. mexicanum. A) Vista panorámica de una sección del ovario y de los diferentes tipos de folículos que los componen (de color azul: folículos previtelogénicos, de color rojo: folículos vitelogénicos y de color blanco: folículos atrésicos. H-E. Bar $=1000 \mu \mathrm{m}$. B) Epitelio germinal (flecha) y folículos previtelogénicos (citoplasma azul). $\mathrm{H}-\mathrm{E}$. Bar $=100 \mu \mathrm{m} \mathrm{C}$ ) Folículos vitelogénicos (citoplasma rojo) y folículos atrésicos (flecha). H-E. Bar $=200 \mu \mathrm{m}$. D) Foliculos postovulatorios (flecha). H-E. Bar $=50 \mu \mathrm{m}$. E) Foliculo atrésico (flecha). H-E. Bar $=100 \mu \mathrm{m}$. 


\subsection{Ovogénesis.}

\section{Estadio I: Proliferación de ovogonias.}

Las ovogonias $(13.327 \pm 2.961 \mu \mathrm{m})$ (Fig. 3D) son células que presentan un núcleo ovalado y escaso citoplasma de tonalidad hialina. Se localizan a lo largo del epitelio germinal ya sea de forma aislada o conformando agrupaciones celulares en conjunto con los ovocitos cromatina-nucléolo y las células prefoliculares, denominadas nidos germinales (Fig. 3C), los cuales son extensiones del epitelio germinal que se proyectan hacia el estroma ovárico. Estas agrupaciones de células se forman mediante una serie de divisiones mitóticas sucesivas de las ovogonias, que se encargan de restaurar la población de células germinales durante cada ciclo reproductor.

\section{Estadio II: Cromatina-nucléolo.}

Conforme las ovogonias van dividiéndose, se diferencian en ovocitos primarios en cromatina-nucléolo $(26.230 \pm 8.949 \mu \mathrm{m})$. Estas células presentan un núcleo redondeado con fibras de cromatina bien marcadas con un nucléolo, su citoplasma es escaso y de tonalidad hialina (Fig. 3E). En este estadio los ovocitos experimentan las etapas de la primera división de la meiosis hasta la etapa de diplóteno temprano, donde se presenta el primer arresto meiótico. Los ovocitos en diplóteno presentan citoplasma hialino y núcleo ovalado con cromosomas plumosos (Fig. 3F). A la par del proceso de diferenciación de los ovocitos, las células prefoliculares van rodeando a los ovocitos en desarrollo, aislándolos unos de otros en un proceso denominado foliculogénesis, donde las células prefoliculares se diferenciarán en las células foliculares, las cuales se encuentran rodeando a los ovocitos en desarrollo; lo que dará lugar a la formación de los folículos ováricos (Fig. 3B). 


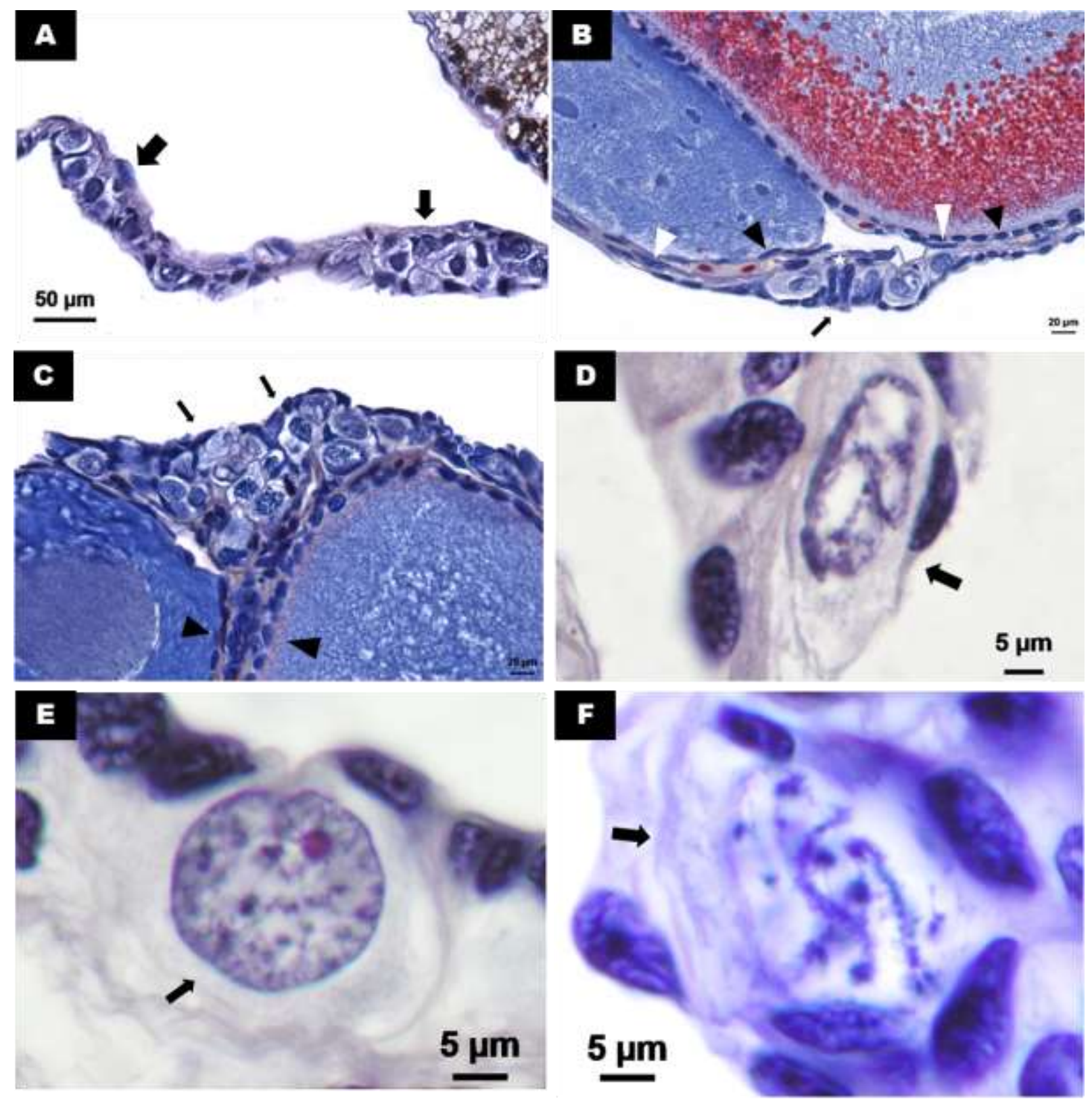

Figura 3. Epitelio germinal de A. mexicanum. A) Vista panorámica del epitelio germinal (flechas negras). $\mathrm{H}-\mathrm{E}$. Bar $=50 \mu \mathrm{m}$. B y C) Nidos germinales junto a folículos en diferentes grados de desarrollo. Nido germinal (flecha negra), células prefoliculares (estrella), células foliculares en su forma aplanada y cúbica (triangulo negro) y células de la teca (triangulo blanco). $\mathrm{H}-\mathrm{E}$. Bar $=20 \mu \mathrm{m}$. D) Ovogonia (flecha negra). $\mathrm{H}-\mathrm{E}$. Bar $=5 \mu \mathrm{m}$. E) Ovocito primario en estadio cromatina-nucléolo (flecha negra). $\mathrm{H}-\mathrm{E}$. Bar $=5 \mu \mathrm{m}$. F) Ovocito primario en diploteno temprano (flecha). H-E. Bar $=5 \mu \mathrm{m}$. 


\section{Estadio III: Crecimiento primario o Previtelogénesis.}

Este estadio se caracteriza por una actividad de síntesis y la acumulación de ARN heterogéneo en el ovoplasma, por lo que se observa un incremento del volumen del mismo y le da una naturaleza basófila. Este estadio comprende dos etapas: Previtelogénesis I y Previtelogénesis II.

Los folículos ováricos en previtelogénesis I (47.269 $\pm 23.695 \mu \mathrm{m})$ (Fig. 4A) se caracterizan por un núcleo esférico grande con cromosomas plumosos y múltiples nucléolos, la concentración de citoplasma es escaso con tonalidad hialina y se encuentra rodeado por células foliculares de morfología aplanada.

Los folículos ováricos en previtelogénesis II (180.161 $\pm 100.45 \mu \mathrm{m})$ (Fig 4B y 4C) presentan un núcleo esférico prominente con varios nucléolos (Fig. 4E) distribuidos en la periferia del mismo, presenta ovoplasma basófilo con la presencia de cuerpos de Balbiani (Fig. 4C y 4F), estructuras temporales de la previtelogénesis que se encuentran cerca de la periferia del núcleo, son ricos en ácidos nucleicos; lo que les da una tonalidad oscura. Las células foliculares siguen conservando una morfología aplanada aunque se comienzan a observar a las células de la teca alrededor del folículo (Fig. 4E).

\section{Estadio IV: Crecimiento secundario o Vitelogénesis.}

Durante este estadio se observa un incremento en el volumen del ovoplasma, así como acumulación de sustancias de reserva provenientes del metabolismo en forma de plaquetas vitelinas. Se observa el desarrollo de la zona pelúcida, una variación en la morfología de las células foliculares y la polarización del ovocito. Este estadio comprende tres etapas: crecimiento secundario temprano o vitelogénesis III, crecimiento secundario medio o vitelogénesis IV y crecimiento secundario tardío o vitelogénesis $\mathrm{V}$.

Los folículos en crecimiento secundario temprano o vitelogénesis III (488.349 \pm 63.807 $\mu \mathrm{m})$ (Fig 5A) presentan un núcleo central prominente con varios nucléolos distribuidos en la periferia, su citoplasma es basófilo y se observa acumulación de plaquetas 
vitelinas acidófilas en la periferia del ovoplasma a modo de anillo. La zona pelúcida se hace visible y comienza a observarse un cambio en la morfología de las células foliculares, cambiando de células planas a células cúbicas y se observa incremento en la vascularización de la teca alrededor del folículo (Fig. 5D).

Los folículos en crecimiento secundario medio o vitelogénesis IV (611.472 \pm 97.897 $\mu \mathrm{m})$ (Fig. 5B) presentan un núcleo prominente con varios nucléolos en la periferia. El tamaño y la concentración de las plaquetas vitelinas acidófilas aumenta considerablemente en comparación con el estadio anterior, solo el ovoplasma que rodea al núcleo permanece libre de plaquetas. Se observa la descentralización del núcleo, ahora denominado vesícula germinal debido al aumento en la concentración de las plaquetas vitelinas. La zona pelúcida presenta un aumento en su grosor (4.291 $\pm 1.229 \mu \mathrm{m}$ ), mientras que las células foliculares mantienen morfología cúbica y el grado de vascularización de la teca es similar a la etapa anterior (Fig. 5E).

Los folículos en crecimiento secundario tardío o vitelogénesis V (1065.815 \pm 128.812 $\mu \mathrm{m}$ ) (Fig. 5C) presentan una vesícula germinal prominente con varios nucléolos distribuidos a lo largo de su periferia, y continúa su migración hacia el polo animal. El citoplasma se encuentra saturado de plaquetas vitelinas y se comienza a observar la polarización del ovocito con las plaquetas vitelinas más grandes en el polo vegetal mientras que las más pequeñas se concentran en el polo animal, donde también se observa la presencia de algunos gránulos pigmentarios. La zona pelúcida aumenta su grosor $(5.214 \pm 1.269 \mu \mathrm{m})$, ahora siendo fácilmente reconocibles la zona radiada y la capa homogénea. Las células foliculares mantienen su morfología cúbica y aumenta la vascularización de la teca (Fig. 5F). 

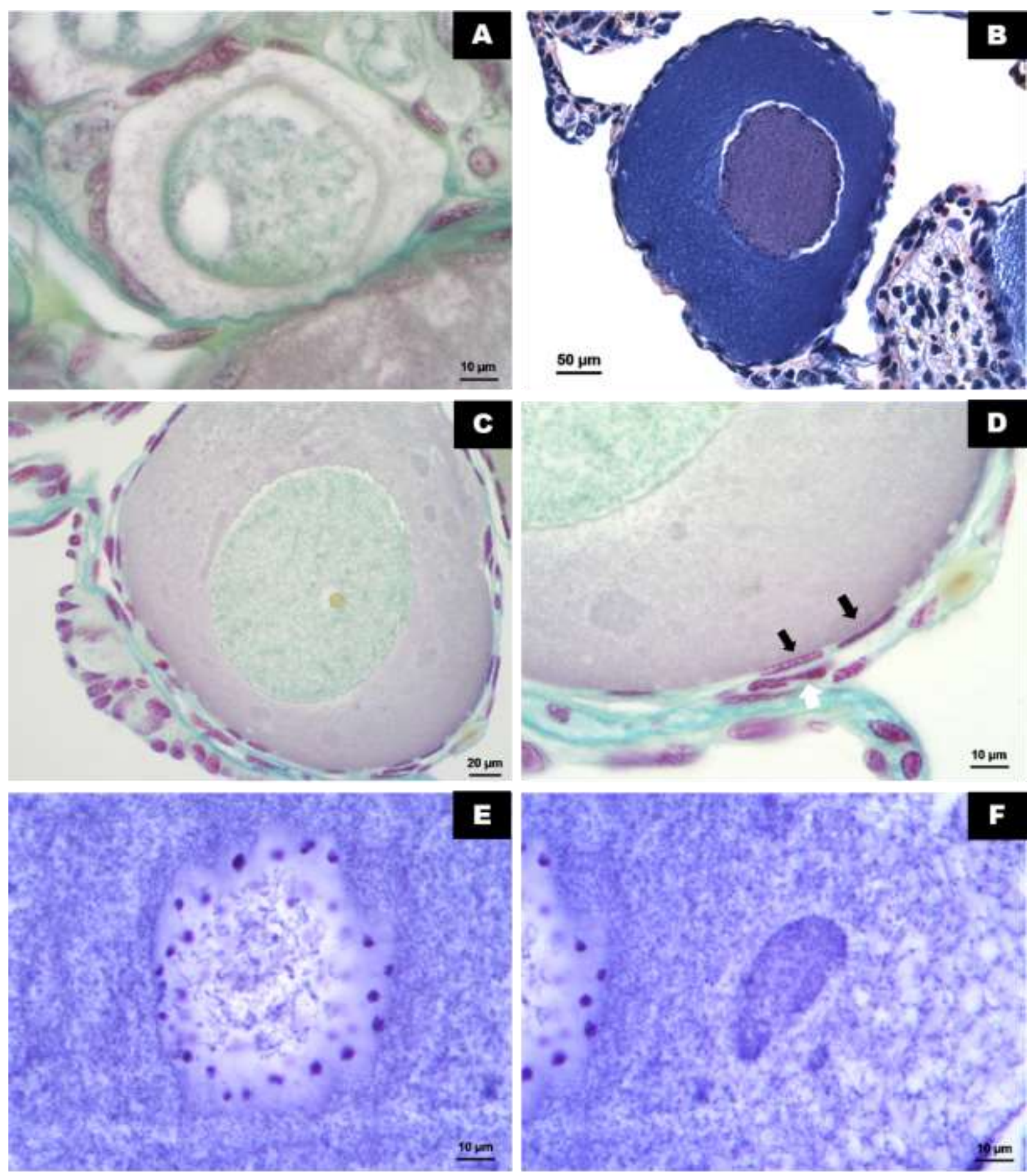

Figura 4. Folículos en crecimiento primario o previtelogénesis. A) Folículo en previtelogénesis $I$. T-Gall. Bar $=$ $10 \mu \mathrm{m}$. B y C. Folículos en previtelogénesis II. En la imagen C se observan a la cuerpos de Balbiani de una coloración mas oscura que el citoplasma. $B=H-E$. Bar $=50 \mu \mathrm{m} . \mathrm{C}=\mathrm{T}$-Gall. Bar $=20 \mu \mathrm{m}$. D) Células foliculares aplanadas (flecha negra) y célula de la teca (flecha blanca), características del crecimiento primario. T-Gall. Bar $=10 \mu \mathrm{m}$. E) Núcleo de un ovocito en previtelogénesis II. Se observan los cromosomas plumosos y nucléolos perinucleares. $\mathrm{H}-\mathrm{E}$. Bar $=10 \mu \mathrm{m}$. F) Cuerpo de Balbiani, caracteristico del crecimiento primario. $\mathrm{H}-\mathrm{E}$. Bar $=10 \mu \mathrm{m}$. 

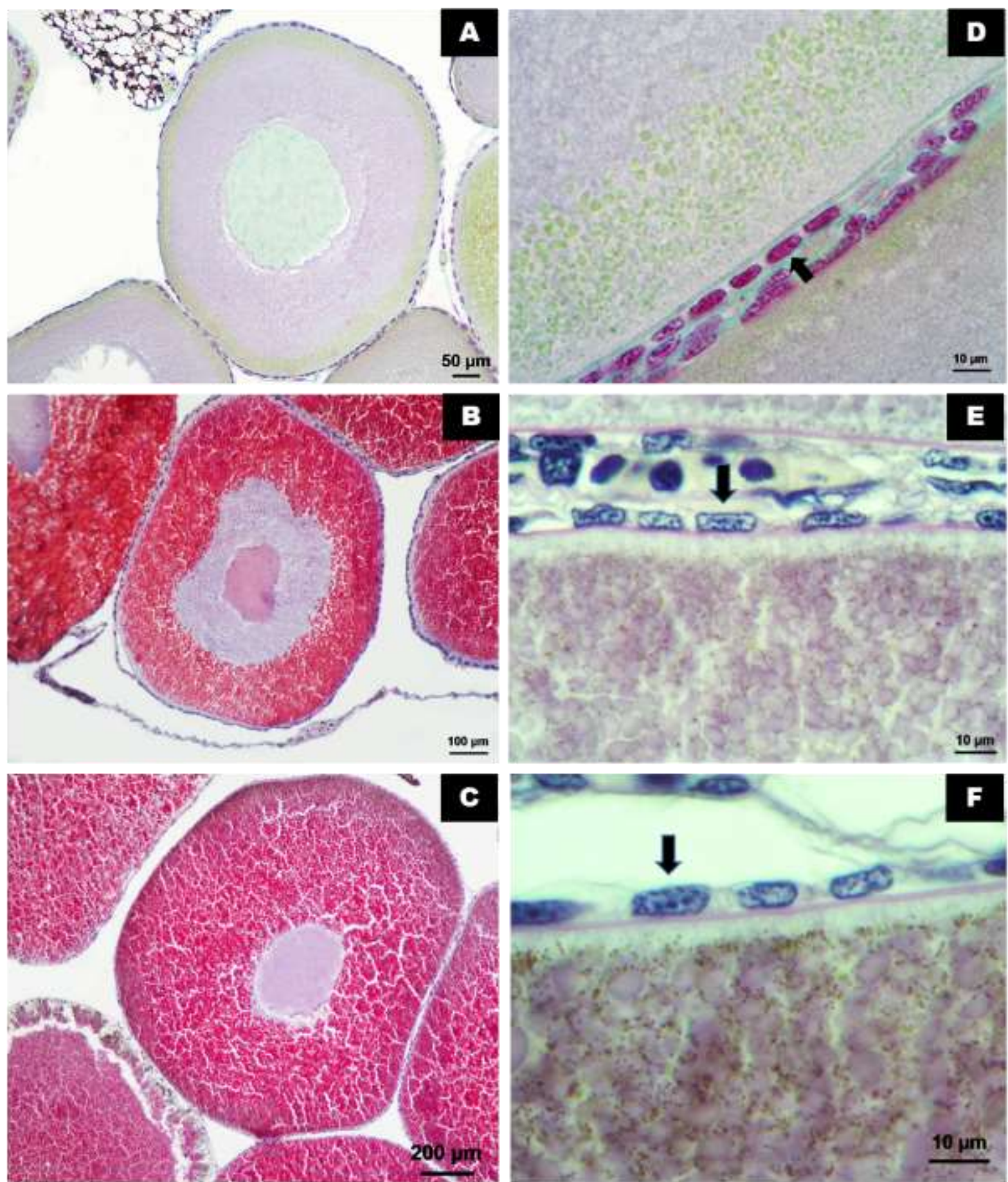

Figura 5. Foliculos en crecimiento secundario o vitelogénesis. A) Foliculo en vitelogénesis III. Se observa la aparición de plaquetas vitelinas en la periferia del ovocito. T-Gall. Bar $=50 \mu \mathrm{m}$. B) Foliculo en vitelogénesis IV. Se caracteriza por la un incremento en la concentración de plaquetas vitelinas. $\mathrm{H} \cdot \mathrm{E}$. Bar $=100 \mu \mathrm{m}$. C) Foliculo en vitelogénesis V. Las plaquetas vitelinas ocupan la totalidad del citoplasma. $\mathrm{H}-\mathrm{E}$. Bar $=200 \mu \mathrm{m}$. B, D y F. Celulas foliculares y zona pelúcida. Durante el crecimiento primario, las celulas foliculares adquieren una morfologia cúbica (flecha). La zona pelúcida de hace presente como una región de intercambio de nutrientes entre el ovocito y las células foliculares. En la vitelogénesis III (B) se le observa como una zona intensamente teñida entre el ovocito y las células foliculares, mientras que en la vitelogénesis IV (D) y V (F) esta se divide en dos zonas: la zona radiata, región estriada en contacto directo con la membrana del ovocito y la capa homogénea, región intensamente teñida en contacto con las células foliculares. D) T-Gall. Bar $=10 \mu \mathrm{m}$. E y F) PAS. Bar $=10 \mu \mathrm{m}$. 


\section{Estadio V: Ovocito Preovulatorio}

El ovocito preovulatorio $(1443.357 \pm 163.567 \mu \mathrm{m})$ (Fig. $6 \mathrm{~A})$ es la etapa final del proceso de ovogénesis. La migración de la vesícula germinal ha finalizado, el citoplasma está completamente saturado de plaquetas vitelinas y la polaridad del ovocito es claramente evidente, siendo que el polo animal se caracteriza por la presencia de la vesícula germinal, gran concentración de gránulos pigmentarios y plaquetas vitelinas pequeñas, en comparación, el polo vegetal presenta plaquetas vitelinas de mayor tamaño y menor concentración de gránulos pigmentarios. Se observa una reducción tanto en el grosor de la zona pelúcida $(2.533 \pm 0.476 \mu \mathrm{m})$, así como en la altura de las células foliculares, que retoman una morfología aplanada (Fig. 6B); la vascularización de la teca es similar al estado anterior.

\section{Folículo Postovulatorio.}

Posterior a la ovulación, el resto del folículo colapsa, convirtiéndose en un folículo postovulatorio (Fig. 6C). Este se caracteriza por la hipertrofia de las células foliculares, las cuales son rodeadas por una capsula de tejido conjuntivo fibroso, derivado de la teca, rodeando a las células foliculares hipertrofiadas, las cuales se van conglomerando conforme el folículo colapsa y es reabsorbido por el estroma ovárico (Fig. 6D).

\section{Atresia Folicular.}

En los diferentes estadios de la ovogénesis se observó a varios ovocitos en un proceso de degeneración, denominado atresia. Este se caracteriza por la pérdida del contorno regular del ovocito así como del plegamiento y la ruptura de la zona pelúcida (Fig. 7A). Posteriormente se observa una proliferación e hipertrofia de las células foliculares y de la teca (Fig. 7B y 7C). Las células foliculares hipertrofiadas fagocitan progresivamente el ovoplasma (Fig. 7D). A la par se observa la compactación del folículo atrésico en un proceso de degeneración y desaparición que va acompañado de la aparición de cuerpos pigmentarios, los cuales se distribuyen a lo largo del folículo atrésico en desaparición (Fig. 7E y 7F). 

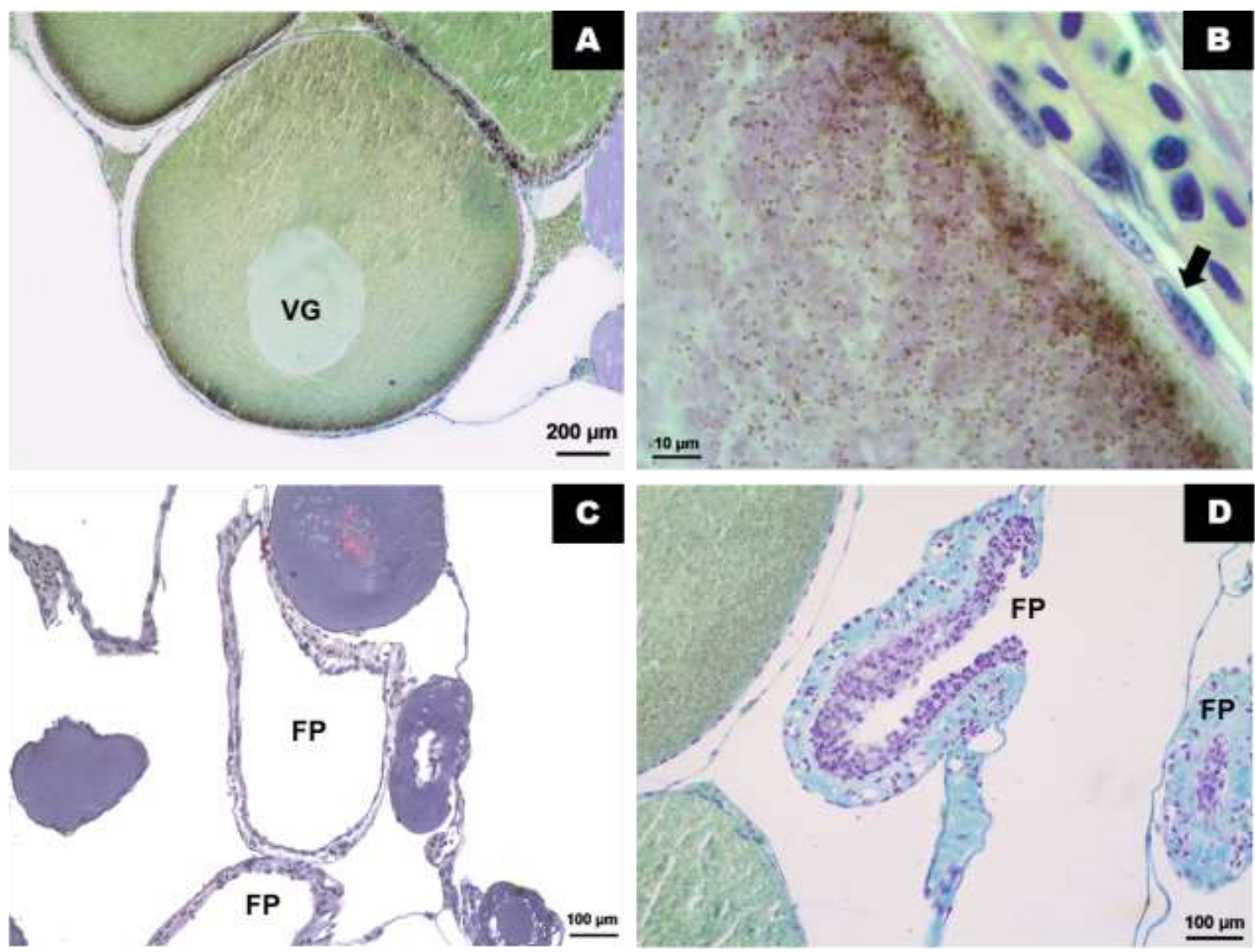

Figura 6. Folículo preovulatorio y postovulatorio. A) Folículo preovulatorio. Presenta un citoplasma saturado en su totalidad por plaquetas vitelinas. La vesicula germinal (VG) se localiza en el polo animal, donde se observa una gran concentración de cuerpos pigmentarios (franja oscura). T-Gall. Bar $=200 \mu \mathrm{m}$. B) Células foliculares y zona de pelúcida de un folículo preovolutario. Las células foliculares (flecha) presentan una forma aplanada y la zona pelúcida a reducido su grosor. PAS. Bar $=10 \mu \mathrm{m}$. C) Foliculos postovulatorios (FP). Se observa el espacio vacío dejado por el ovocito rodeado por las células foliculares y de la teca. $\mathrm{H}-\mathrm{E}$. Bar $=100 \mu \mathrm{m}$. D) Colapso del foliculo. Se observa una conglomeración de las células foliculares conformo el folículo va reduciendo su área. Alrededor de ellas de observa una capsula fibrosa de tejido conjuntivo, constituido por las células de la teca hipertrofiadas. T-Gall. Bar $=100 \mu \mathrm{m}$. 

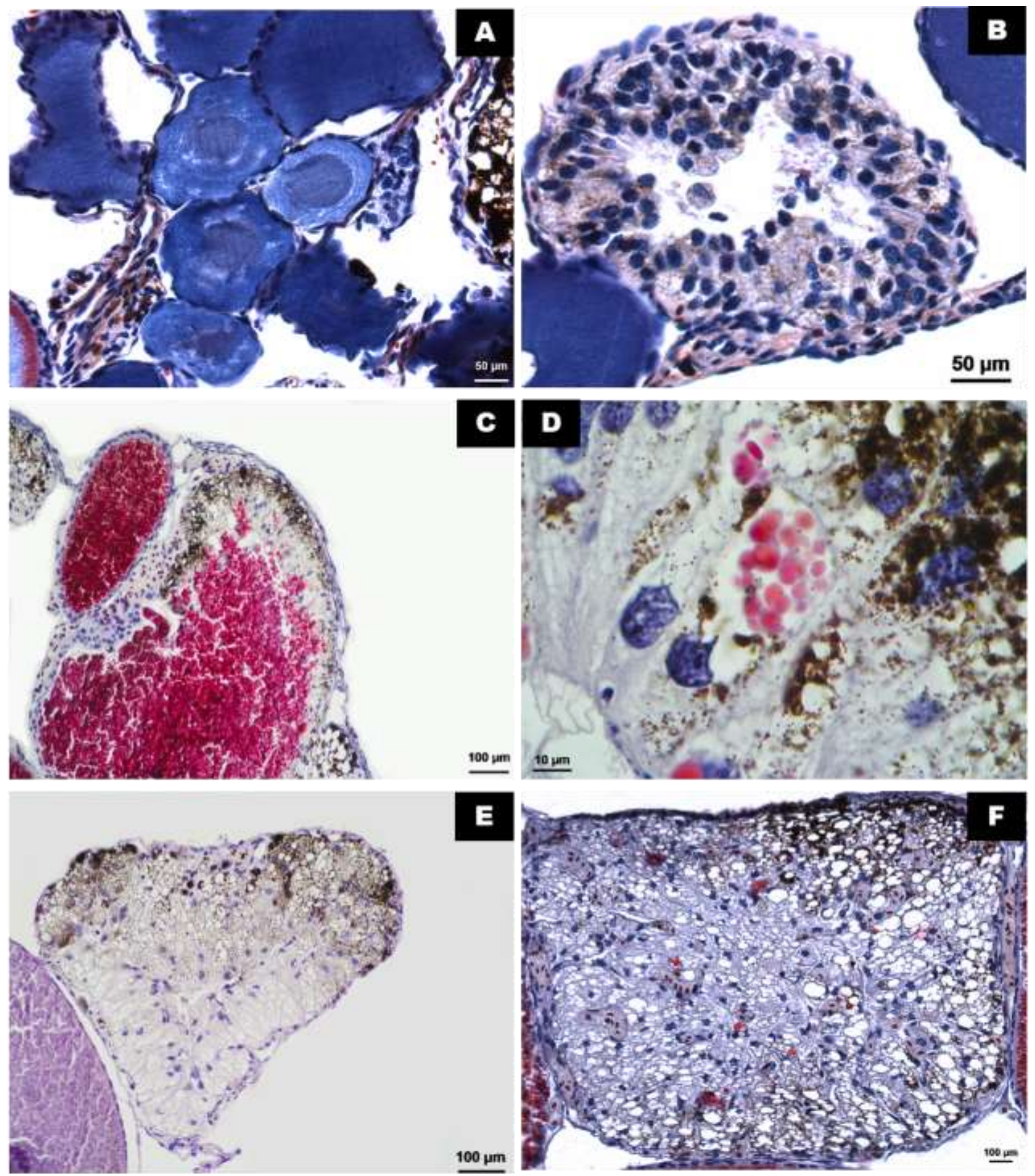

Figura 7. Atresia folicular. A) foliculos previtelogénicos (azul) perdiendo el contorno celular. $\mathrm{H}-\mathrm{E}$. Bar $=50 \mu \mathrm{m}$. B) Proliferación de las células foliculares hacia el interior del foliculo. $\mathrm{H}-\mathrm{E}$. Bar $=50 \mu \mathrm{m}$. C) Foliculo vitelogénico en atresia, se observa la proliferación e hipertrofia de las células foliculares en la parte superior del folículo. H-E. Bar $=100 \mu \mathrm{m}$. D) Fagocitosis del ovoplasma por parte de las células foliculares hipertrofiadas y pigmentadas. $\mathrm{H}$ E. Bar $=10 \mu \mathrm{m}$. E y F) Colapso del folículo atrésico. En la imagen $\mathrm{E}$ se observa a las células foliculares hipertrofiadas y algunas con cuerpos pigmentarios, distribuirse alrededor de un espacio apenas visible. En la imagen $\mathrm{F}$ ya no se observa ningún espacio, solo a las células foliculares y de la teca hipertrofiadas, con algunos vasos sanguineos. E) PAS. Bar $=100 \mu \mathrm{m}$. F) $\mathrm{H}-\mathrm{E} . \mathrm{Bar}=100 \mu \mathrm{m}$. 


\subsection{Características morfológicas de la cloaca}

La cloaca de $A$. mexicanum es una estructura cilíndrica (Fig. 8A) donde convergen las porciones distales de los conductos digestivo, excretores y reproductores, comunicándolos con el exterior. La cloaca está dividida en dos regiones: el conducto cloacal (Fig. 8B), que es la porción craneal de la cloaca, a la que desembocan los conductos excretores y reproductores y presenta una forma cilíndrica y la región caudal de la cloaca, la cámara cloacal (Fig 8C), que es un espacio más amplio que se comunica con el medio externo. Tanto el conducto como la cámara cloacal están delimitados internamente por epitelio columnar estratificado que presenta células ciliadas localizadas en el techo cloacal y células secretoras, las cuales no presentan una distribución restringida dentro de la cloaca (Fig 9A y 9B); este epitelio presentó actividad secretora a lo largo del ciclo, reaccionando positivamente tanto a PAS como a azul alciano (Fig. 9C y 9D). Dentro de la cloaca hay tres tipos de glándulas túbulo-alveolares, la cuales se proyectan desde el epitelio cloacal hacia la túnica propia, siendo rodeadas por células mioepiteliales, estas son:

1) Glándulas dorsales (Fig. 10A), localizadas en la parte craneal de la cloacal y proyectándose hacia la pared dorsal, estas glándulas están delimitadas internamente por epitelio cúbico simple, presenta núcleos ovalados y escaso citoplasma con reacción positiva a azul alciano (Fig. 10B y 10C).

2) Glándulas ventrales (Fig. 10D), son las glándulas más grandes de la cloaca, se encuentran ubicadas en grupos desde la porción media del conducto cloacal hasta la cámara cloacal, ocupando la región ventro-lateral a ambos lados del lumen (Fig 8B y $8 \mathrm{C}$ ), la unidad secretora de estas glándulas se encuentra revestida por epitelio columnar alto con citoplasma eosinófilo y núcleos basales, presentando una reacción positiva a PAS (Fig. 10F), mientras que el túbulo secretor de esta glándula presenta un epitelio cúbico simple (Fig. 10E).

3) Espermatecas (Fig. 11A) son un grupo de glándulas localizadas a lo largo de la cloaca, ocupando la región dorso-lateral de la misma (Fig 8B y 8C), la unidad secretora presenta epitelio columnar bajo con citoplasma eosinófilo y núcleos ovalados basales, 
presenta una reacción positiva a PAS (Fig. 11B). El túbulo secretor de la espermateca presenta un epitelio cúbico simple y parece albergar espermatozoides por cortos periodos de tiempo (tres días) (Fig. 11C, 11D y 11E).

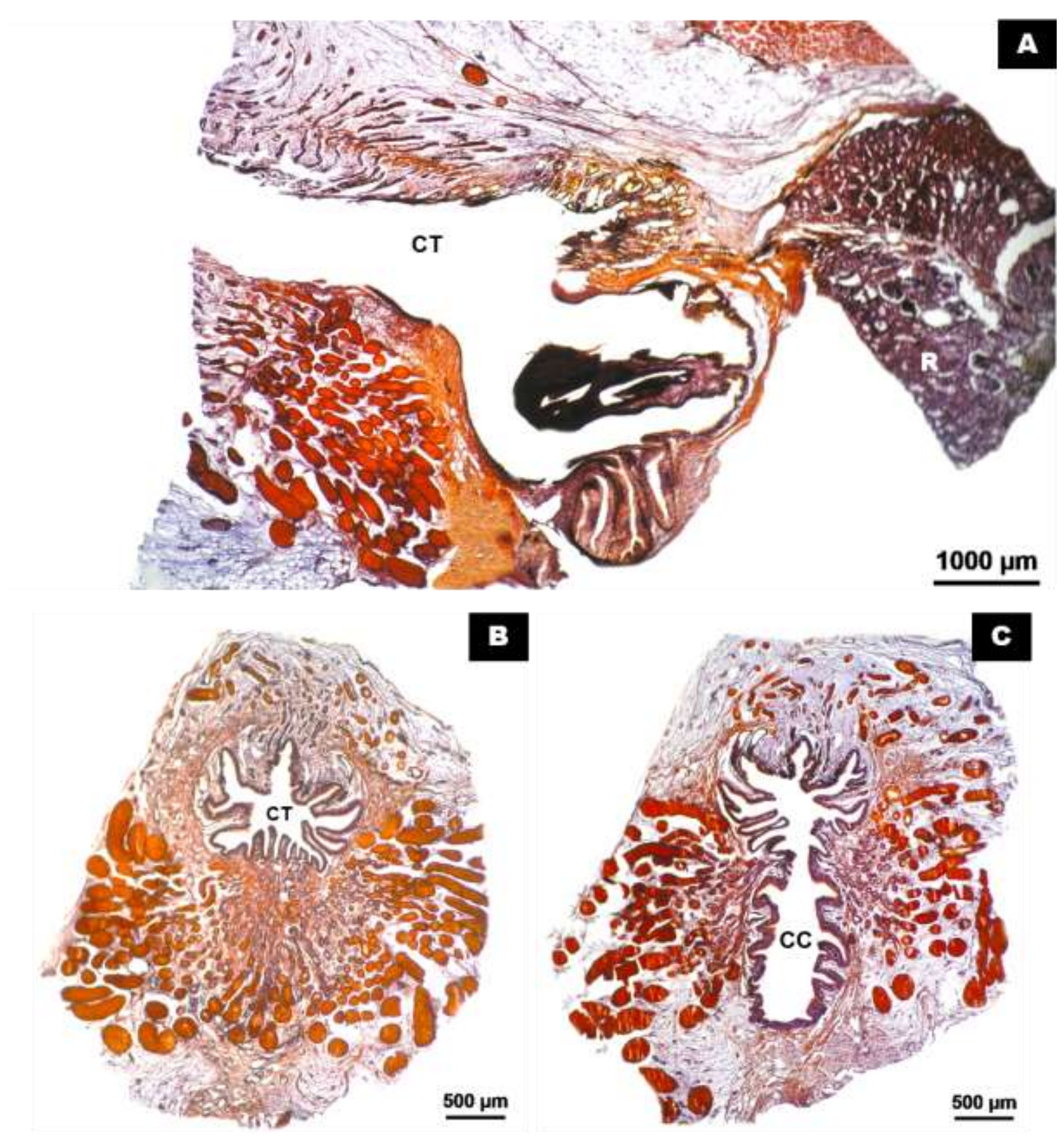

Figura 8. Histologia de la cloaca de A. mexicanum. A) Vista longitudinal de la cloaca. Las espermatecas se localizan en la parte superior del conducto cloacal, mientras que las glándulas ventrales se localizan en la parte inferior. CT: Conducto cloacal. R: Riñón H-E. Bar $=1000 \mu \mathrm{m}$. B) Vista transversal del conducto cloacal (CT). Espermatecas en la parte superior. Glándulas ventrales en la parte inferior. H-E. Bar $=500 \mu \mathrm{m}$. C) Vista transversal de la cámara cloacal (CC). Espermatecas en la parte superior. Glándulas ventrales a los laterales. $\mathrm{H}-\mathrm{E} . \mathrm{Bar}=500 \mu \mathrm{m}$. 

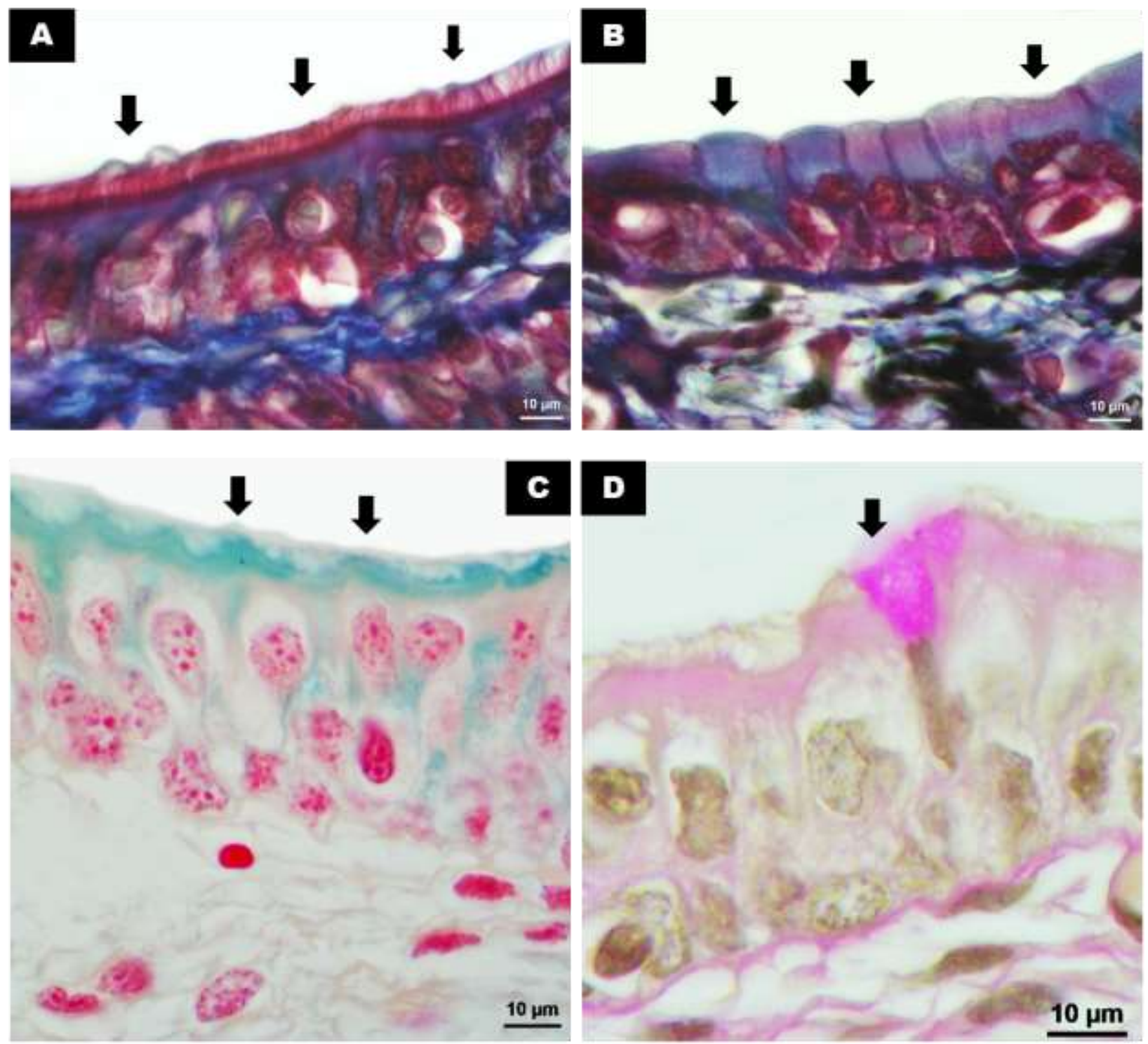

Figura 9. Características del epitelio cloacal. A) Epitelio biestratificado con células ciliadas (Flecha). T-Mas. Bar= $10 \mu \mathrm{m}$. B) Epitelio biestratificado con células secretoras (Flecha). T-Mas. Bar=10 $\mu \mathrm{m}$. C y D) Presencia de mucopolisacáridos ácidos (C) y neutros (D) en el epitelio cloacal (Flecha). C) A.A. Bar=10 $\mu \mathrm{m}$. D) PAS. Bar= 10 $\mu \mathrm{m}$. 

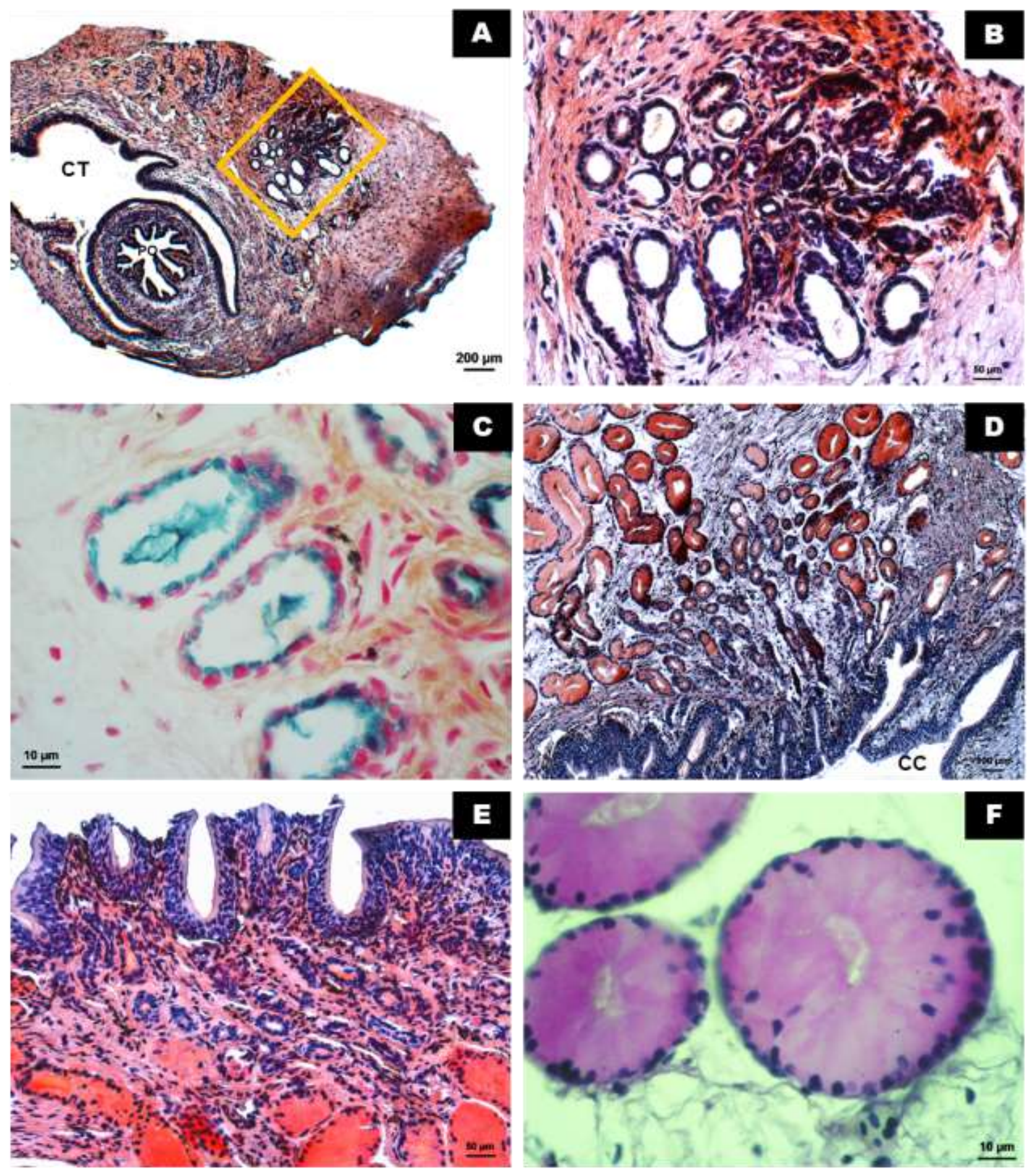

Figura 10. Glándulas cloacales. A) Vista de la transición entre la papila oviductal (PO) y el conducto cloacal (CT), dentro del recuadro amarillo se observan las glándulas dorsales. H-E. Bar $=200 \mu \mathrm{m}$. B) Glándulas dorsales. $\mathrm{H}-\mathrm{E}$. Bar $=50 \mu \mathrm{m}$. C) Mucopolisacáridos ácidos en el epitelio secretor cúbico de las glándulas dorsales. A.A. Bar $=10 \mu \mathrm{m}$. D) Vista parcial de la cámara cloacal $(\mathrm{CC})$ y de las glándulas ventrales. $\mathrm{H}-\mathrm{E} . \mathrm{Bar}=$ $100 \mu \mathrm{m}$. E) Vista del túbulo secretor de las glándulas ventrales desembocando hacia el lumen de la cámara cloacal. $\mathrm{H}-\mathrm{E}$. Bar $=50 \mu \mathrm{m}$. F) Mucopolisacáridos neutros en el epitelio columnar de las glándulas ventrales. PAS. Bar $=200 \mu \mathrm{m}$. 


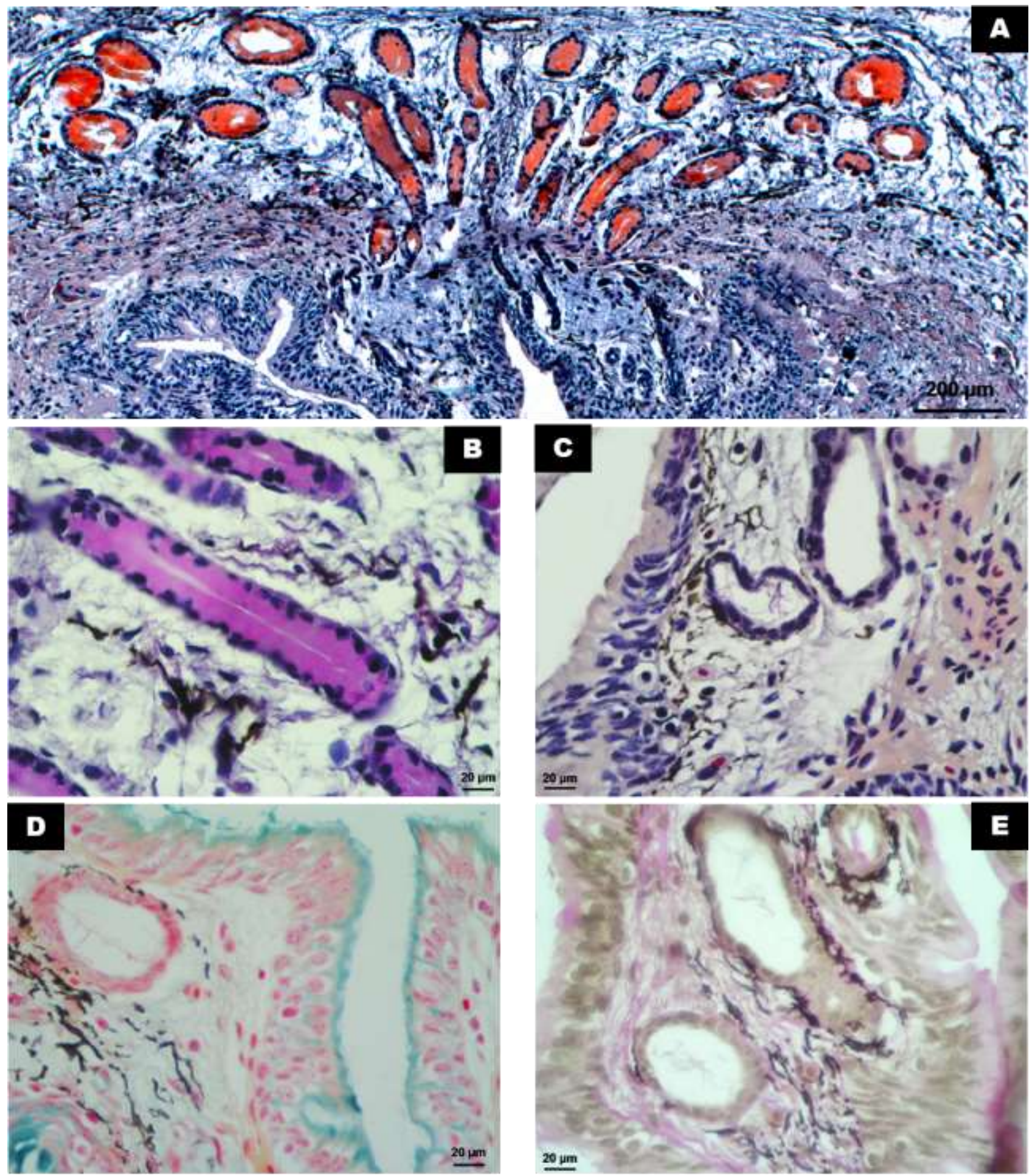

Figura 11. Espermateca. A) Vista panorámica de las espermatecas en la pared dorsal de la cloaca y su conexión al lumen. $\mathrm{H}-\mathrm{E}$. Bar $=200 \mu \mathrm{m}$. B) Mucopolisacáridos neutros en el columnar de la espermateca. PAS. Bar $=20 \mu \mathrm{m}$. C, D y E. Espermatozoides dentro del túbulo secretor de la espermateca. C) H-E. Bar $=20 \mu \mathrm{m}$. D) A.A. $B a r=20 \mu \mathrm{m}$ E) PAS. Bar $=20 \mu \mathrm{m}$. 


\subsection{Variaciones estaciones del ciclo reproductor de Ambystoma mexicanum.}

A lo largo del ciclo reproductor de $A$. mexicanum no se observaron diferencias significativas con respecto a la longitud de los ovarios (ANOVA, $F(3,13)=2.212 ; p=$ 0.135). (Fig. 12). La mayoría de los diferentes tipos de folículos estuvieron presentes a lo largo del ciclo, sin embargo, se observaron variaciones en la proporción entre cada uno de ellos durante cada estación (Fig. 13). No se observaron diferencias significativas en el diámetro de la espermateca a lo largo del ciclo anual (ANOVA, $F(3,44)=1.695 ; p=0.182$ ), ni en la altura de su epitelio (ANOVA, $F(3,44)=0.402 ; p$ $=0.752)$ (Fig 14), este último presentó reacción positiva a PAS durante todas las estaciones (Fig. 15).

En verano la longitud promedio de los ovarios fue de $4.750 \pm 1.218 \mathrm{~cm}$ (Fig. 12), con una proporción de ovocitos previtelogénicos de 32\% (8\% previtelogénesis I, 24\% previtelogénesis II), $37 \%$ vitelogénicos (21\% vitelogénesis III, $6 \%$ vitelogénesis IV, $10 \%$ vitelogénesis $\mathrm{V}$ ), $7 \%$ preovulatorios, y $24 \%$ atrésicos (Fig. 13). El diámetro de la espermateca fue de $82.400 \pm 14.895 \mu \mathrm{m}$ mientras que la altura del epitelio fue de $28.182 \pm 6.361 \mu \mathrm{m}$ (Fig. 14).

En otoño, la longitud promedio de los ovarios fue de $5.725 \pm 1.053 \mathrm{~cm}$ (Fig. 12). La proporción de ovocitos previtelogénicos fue similar a la estación pasado (32\%), aunque hubo un cambio entre las proporciones de ovocitos previtelogénicos I II (3\% previtelogénesis I $3 \%$, previtelogénesis II 29\%), se observó un aumento en la proporción de folículos vitelogénicos (45\%) (17\% vitelogénesis III, 10\% vitelogénesis IV, 17\% vitelogénesis V), así como de folículos preovulatorios (14\%) pero el porcentaje de folículos atrésicos se redujo (9\%) (Fig. 13). El diámetro de la espermateca presentó un ligero aumento $(87.585 \pm 26.505 \mu \mathrm{m})$ en comparación a la estación pasada. Lo mismo se observa con la altura del epitelio de la espermateca $(29.862 \pm 7.394 \mu \mathrm{m})$ (Fig. 14).

En invierno, la longitud promedio de los ovarios fue de $6.400 \pm 1.698 \mathrm{~cm}$ (Fig. 12). La proporción de ovocitos previtelogénicos fue del $31 \%$, siendo los 
previtelogénesis II los más abundantes, aunque con un incremento de los previtelogénesis I (9\% previtelogénesis I, 22\% previtelogénesis II). Se observó una reducción en el porcentaje de ovocitos vitelogénicos (29\%; $8 \%$ vitelogénesis III, $6 \%$ vitelogénesis IV, $15 \%$ vitelogénesis $\mathrm{V}$ ), así como aumento en el porcentaje de folículos preovulatorios $(22 \%)$, solo en esta estación se observaron folículos postovulatorios (7\%) y una ligero aumento en el porcentaje de folículos atrésicos (11\%) en comparación con la estación pasada (Fig. 13). Lo mismo ocurre para el diámetro de la espermateca $(94.590 \pm 29.116 \mu \mathrm{m})$ y la altura del epitelio de la espermateca (30.420 $\pm 10.143 \mu \mathrm{m}$ ), que presentaron ligero incremento a comparación con la estación pasada (Fig. 13). Solo en esta estación se reportó la presencia de espermatozoides dentro de la espermateca de una hembra (Fig. 11C, 11D y 11F) tres días después de colectar el espermatóforo.

Durante la primavera, la longitud promedio de los ovarios fue de $7.200 \pm 0.700$ cm (Fig. 12). Se observó un aumento en la proporción de ovocitos previtelogénicos (38\%; $2 \%$ previtelogénesis I, 35\% previtelogénesis II), el porcentaje de ovocitos vitelogénicos se redujo considerablemente en comparación a las estaciones pasadas ( $9 \% ; 7 \%$ vitelogénesis III, $1 \%$ vitelogénesis IV, $2 \%$ vitelogénesis $\mathrm{V}$ ), se observó la presencia de folículos preovulatorios (24\%), así como un incremento en la proporción de folículos atrésicos (29\%) (Fig. 13). El diámetro de la espermateca (74.507 \pm 16.111 $\mu \mathrm{m})$ se redujo de manera considerable a la estación pasada, aunque la altura del epitelio de la espermateca $(31.518 \pm 5.698 \mu \mathrm{m})$ fue similar al de la estación pasada (Fig. 14). 


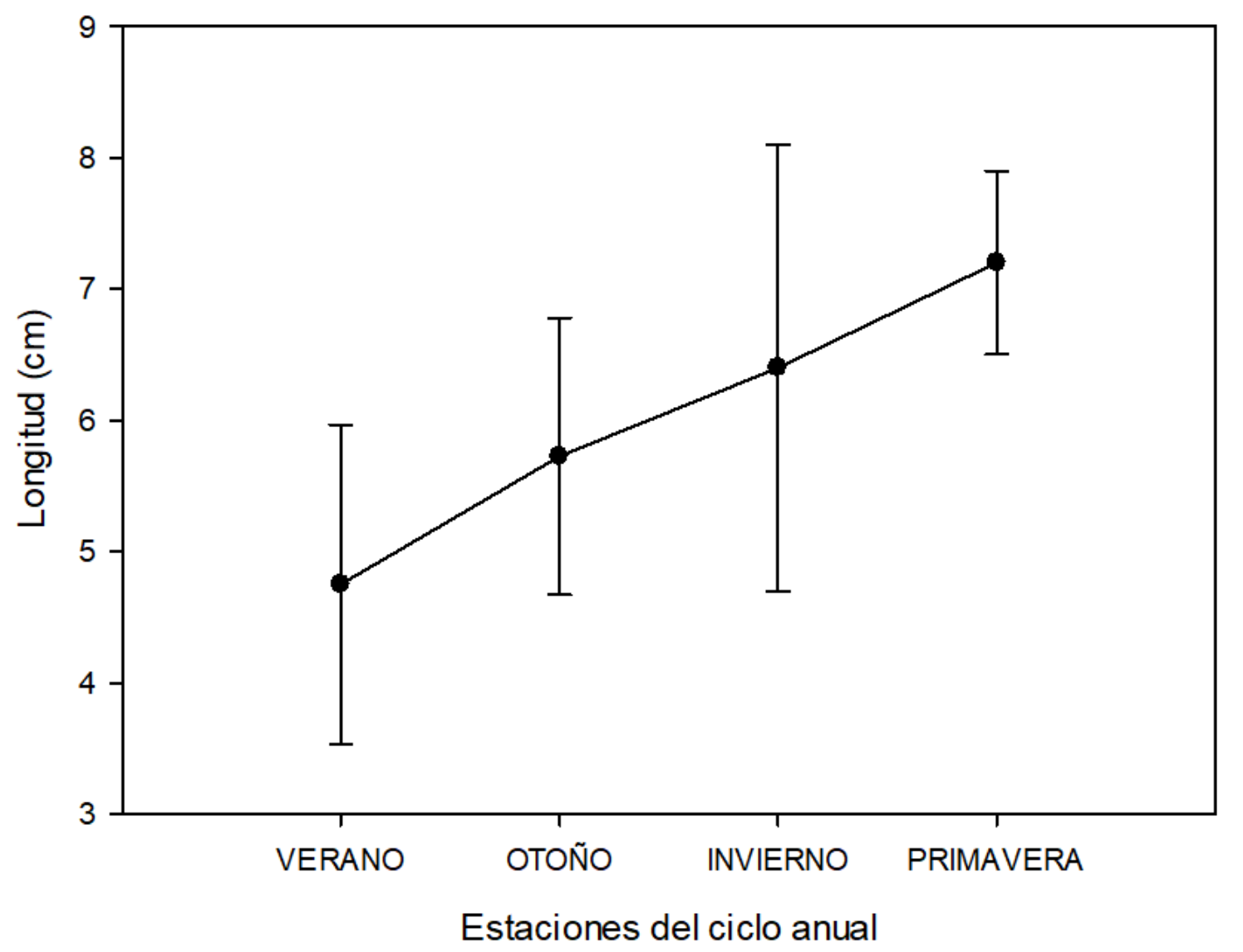

Figura 12. Variaciones estacionales en la longitud de los ovarios de $A$. mexicanum durante un ciclo anual. Verano $(4.750 \pm 1.218 \mathrm{~cm})$, Otoño $(5.725 \pm 1.053 \mathrm{~cm})$, Invierno $(6.400 \pm 1.698 \mathrm{~cm})$, Primavera $(7.200 \pm 0.700 \mathrm{~cm})$. 

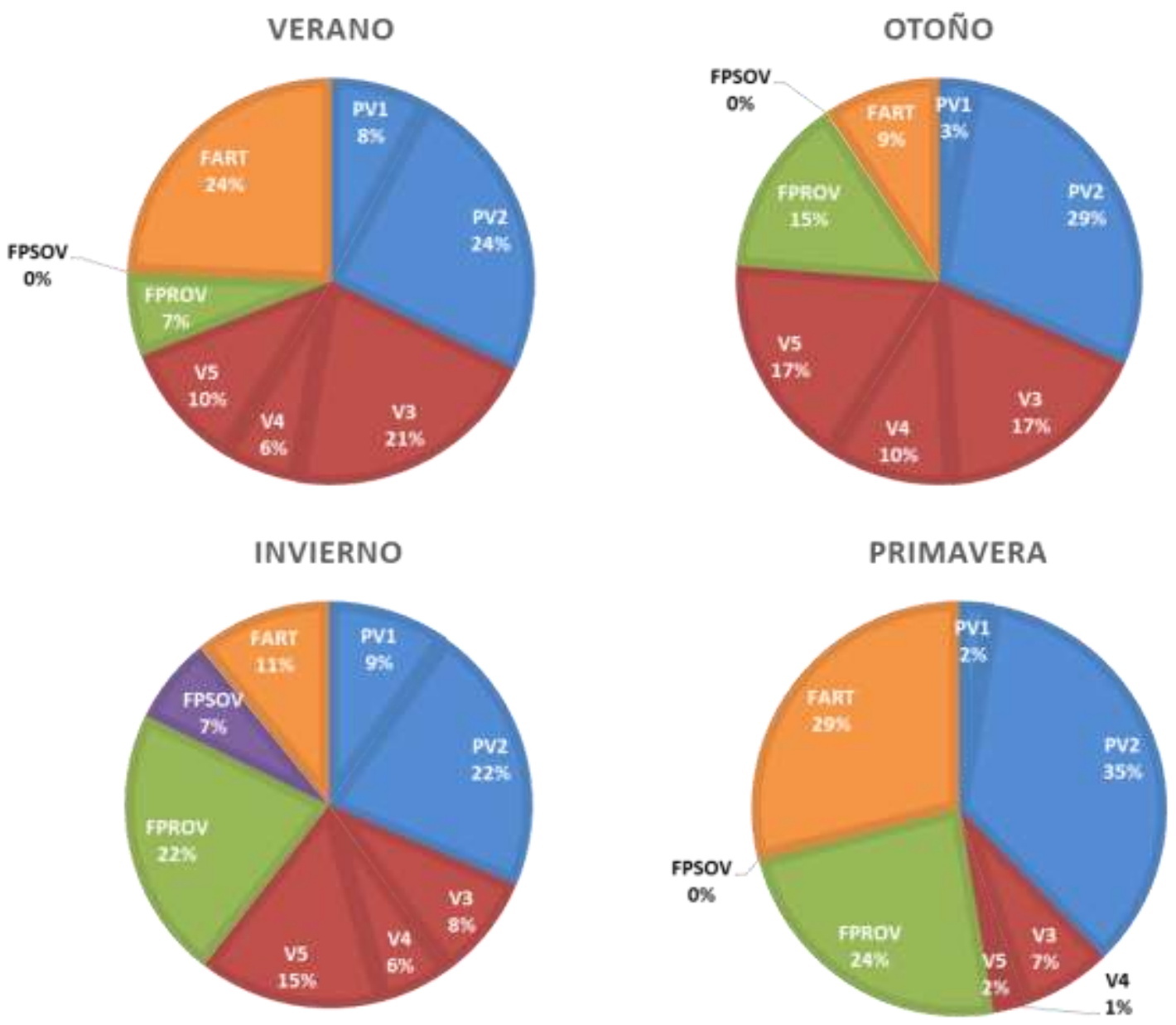

Figura 13. Variaciones estacionales en la proporción de folículos ováricos de $A$. mexicanum durante un ciclo anual. Foliculos previtelogénicos de azul (PV1= Previtelogénesis I, PV2= Previtelogénesis II), Foliculos vitelogénicos de rojo ( $\mathrm{V} 3=$ Vitelogénesis III , V4= Vitelogénesis IV, V5= Vitelogénesis V). Foliculos preovulatorios de verde (FPROV). Foliculos postovularios de morado (FPSOV). Folículos atrésicos de naranja (FART). 


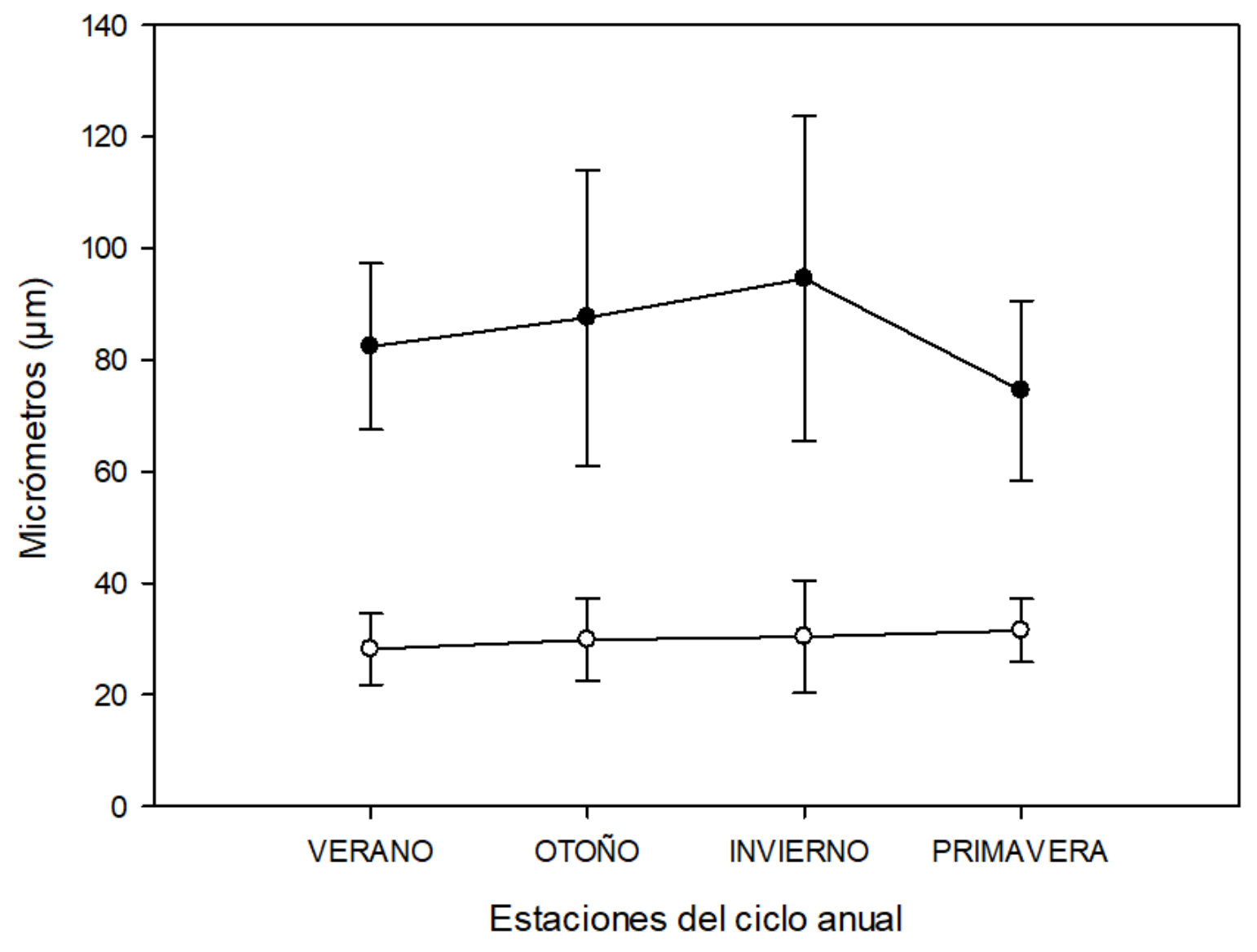

\section{$\longrightarrow$ Diámetro de la espermateca. \\ $-\infty$ - Altura del epitelio de la espermateca.}

Figura 14. Variaciones estacionales en el diámetro de la espermateca y en la altura del epitelio de la espermateca de $A$. mexicanum durante un ciclo anual. Diámetro de la espermateca: Verano $(82.400 \pm 14.895 \mu \mathrm{m})$ Otoño $(87.585 \pm 26.505 \mu \mathrm{m})$ Invierno $(94.590$ $\pm 29.116 \mu \mathrm{m})$ Primavera $(74.507 \pm 16.111 \mu \mathrm{m})$. Altura del epitelio de la espermateca: Verano $(28.182 \pm 6.361 \mu \mathrm{m})$ Otoño $(29.862 \pm 7.394 \mu \mathrm{m})$ Invierno $(30.420 \pm 10.143 \mu \mathrm{m})$ Primavera $(31.518 \pm 5.698 \mu \mathrm{m})$. 

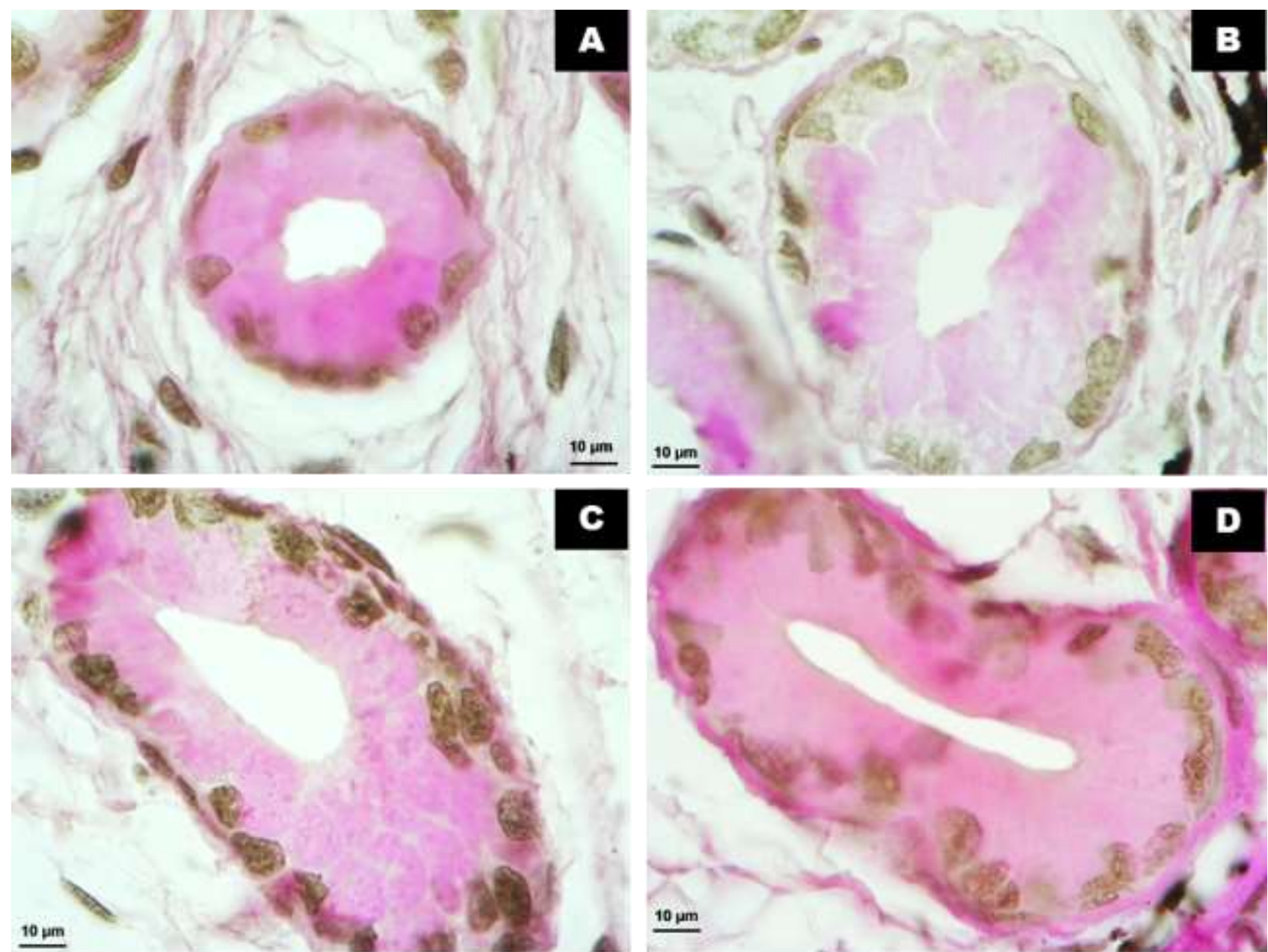

Figura 15. Morfologia de la espermateca a lo largo de un ciclo anual. A) Verano; B) Otoño; C) Invierno y D) Primavera. PAS. Bar $=10 \mu \mathrm{m}$. 


\section{DISCUSIÓN}

\subsection{Morfología del ovario y ovogénesis.}

Los ovarios de Ambystoma mexicanum son estructuras saculares compuestos por varios sacos ováricos con una cámara interna llena de linfa. Esto es similar a lo descrito en otras especies de urodelos (Uribe, 2003, 2009) y anuros (Ogielska y Bartmanska, 2009). La mayoría de los trabajos realizados en diferentes especies de anfibios se centran en la identificación de tres estadios: previtelogénesis, vitelogénesis y postvitelogénesis o maduración del ovocito, que engloban procesos como la proliferación celular y el entrecruzamiento cromosómico en la previtelogénesis (Dumont, 1972; Sharon, Degani y Warburg, 1997). Otros autores incluyen otros estadios como la proliferación de ovogonias, la presencia de ovocitos primarios previos a la foliculogénesis y la atresia folicular. (Oliveira y Santos, 2004; Prado et al. 2004; Yartsev, Exbrayat y Kuranova, 2015; Montezol et al. 2018; Tapia-Guato, 2018). La descripción de la ovogénesis de $A$. mexicanum fue realizada haciendo una modificación de la clasificación propuesta por Grier et al. (2009) para el teleósteo Centropomus undecimalis así como otras especies de peces, dividiéndola en cinco estadios, de acuerdo a diversos criterios morfológicos y a procesos fisiológicos característicos, los cuales son: proliferación de ovogonias, cromatina-nucléolo, crecimiento primario, crecimiento secundario y ovocito preovulatorio.

Las ovogonias de A. mexicanum presentaron una morfología similar a la descrita en otras especies de urodelos como Salamandra salamandra infraimmaculata (Sharon et al. 1997), Salamandrella keyserlingii (Yartsev et al. 2015), Bolitoglossa peruviana (Tapia-Guato, 2018) anuros como Xenopus laevis (Dumont, 1972), Scinax fuscovarius (Oliveira y Santos, 2004) y Rhinella schneideri (Montezol et al. 2018). Se han reportado dos tipos de ovogonias en los anfibios: la ovogonia primaria de núcleo ovalado y la ovogonia secundaria de núcleo redondo, esta última se caracteriza por la presencia de puentes citoplásmicos entre las cohortes de células, la cuales solo se pueden apreciar mediante un análisis ultraestructural (Ogielska y Bartmanska, 2009; Uribe, 2009). En los anfibios al igual que en reptiles y peces, hay una población permanente de 
ovogonias que restauran la población de células germinales en el estroma ovárico a lo largo de la vida de los organismos (Grier et al. 2009; Uribe, 2009; Uribe, HernándezFranyutti, Sanz-Ochotorena y González-Porter, 2010). De acuerdo con Grier et al. (2009) y Uribe (2009), al final de cada ciclo reproductor se observa un incremento en la tasa de división de las ovogonias, lo cual se puede deber a un incremento en la concentración de hormonas esteroideas como los estrógenos o la progesterona.

El estadio de cromatina nucléolo corresponde al desarrollo de los ovocitos primarios hacia la fase diplótena, donde ocurre el primer arresto meiótico. En este estadio se aprecia la compactación de la cromatina, el entrecruzamiento de los cromosomas, la aparición de los cromosomas plumosos, los cuales son fibras de cromatina compactadas que presentan sitios puntuales donde el material genético no está compactado y se pueden realizar los procesos de transcripción y traducción para la síntesis de proteinas. (Uribe, 2003; Grier et al., 2009). A la par, conforme los ovocitos primarios van desarrollándose, las células prefoliculares aledañas lo van rodeando para formar un folículo ovárico. De acuerdo a Ogielska y Bartmanska (2009), las células prefoliculares rodean a los ovocitos durante la fase paquítena; este proceso no concluye sino hasta inicios del crecimiento primario (Grier et al. 2009).

El crecimiento primario o previtelogénesis es un estadio que se caracteriza por una gran actividad de síntesis en el núcleo o autosintesis, evidencia de ello son la presencia de los cromosomas plumosos, el crecimiento exponencial del núcleo y la presencia de múltiples nucléolos distribuidos en la periferia del mismo en los ovocitos previtelogénicos tanto de $A$. mexicanum como de otras especies de anfibios (Dumont, 1972; Sharon et al. 1997; Prado et al. 2004; Oliveira y Santos, 2004; Yartsev et al. 2015; Montezol et al. 2018; Tapia-Guato, 2018). Se ha reportado incremento en la concentración de ARN, en la síntesis de proteinas, fosfolípidos, otros precursores de macromoléculas y de los organelos ovoplásmicos como ribosomas, retículo endoplásmico, aparato de Golgi y mitocondrias. Esto componentes subcelulares y moleculares le dan una naturaleza basófila al citoplasma (Uribe, 2003; Grier et al. 2009). Un elemento característico del crecimiento primario es la aparición de los 
cuerpos de Balbiani, los cuales están constituidos por mitocondrias unidas entre sí gracias a una sustancia denominada cemento intermitocondrial o nuage. Actualmente se desconoce cuál es su función exactamente (Ogielska y Bartmanska, 2009.) En los anuros se ha reportado la presencia de gránulos corticales, los cuales son vesículas que participan en el cambio conformacional de la membrana plasmática, evitando la polispermia (Ogielska y y Bartmanska, 2009). De acuerdo a Charbonneau et al. (1983) no se ha reportado la presencia de gránulos corticales en los ovocitos de los urodelos, lo cual puede ser sustentado en el presente trabajo con las observaciones realizadas en los ovocitos de $A$. mexicanum, donde no se observó la presencia de gránulos corticales, lo que reafirma el estudio realizado por Bordzilovskaya y Dettlaff (1991) quienes reportaron polispermia en los huevos de $A$. mexicanum. Durante el crecimiento primario, las celulas foliculares de $A$. mexicanum mantuvieron una morfología aplanada y en la etapa de previtelogénesis II se pudo apreciar la aparición de la teca. Grier et al. (2009) y Uribe (2009) argumentan que la zona pelúcida comienza a desarrollarse al final de la previtelogénesis. La zona pelúcida es una región rica en glucoproteínas localizada entre el ovocito y las celulas foliculares, la cual se forma a partir de las interdigitaciones de las membranas plasmáticas del ovocitos y las celulas foliculares, aumentando la superficie de contacto entre ellos (Uribe et al. 2010). En los ovocitos en previtelogénesis II de $A$. mexicanum no se aprecia la zona pelúcida, sin embargo, la aparición de la teca es una señal de que la comunicación entre el ovocito y las celulas foliculares es más activa, preparando al folículo para una mayor captación de nutrientes y para la producción y liberación de hormonas.

El crecimiento secundario o vitelogénesis se caracteriza por el crecimiento considerable del ovocito en comparación a los otros estadios. En los folículos en crecimiento secundario de $A$. mexicanum se observaron varios cambios morfológicos notables. Se observó engrosamiento y mayor vascularización en la teca, las células foliculares pasaron de una morfología aplanada a cubica, la zona pelúcida se hace presente y comienza a engrosarse lo largo de la vitelogénesis, diferenciándose en dos regiones: la zona radiata y la capa homogénea y el ovoplasma comienza a saturarse 
de plaquetas vitelinas, las cuales en un principio se localizan en la periferia del ovocito pero conforme trascurre la vitelogénesis, la plaquetas vitelinas se acumulan de manera concéntrica, ocupando la totalidad del ovoplasma y desplazando al núcleo o vesícula germinal junto con el citoplasma activo hacia un región del ovocito denominada polo animal, donde también se observa una acumulación de gránulos pigmentarios. Este proceso es similar a lo descrito en otras especies de anfibios (Dumont, 1972; Sharon et al. 1997; Prado et al. 2004; Oliveira y Santos, 2004; Yartsev et al. 2015; Montezol et al. 2018; Tapia-Guato, 2018). De acuerdo con Uribe (2003), Grier et al. (2009) y Ogielska y Bartmanska (2009), la vitelogénesis se puede definir como un proceso de heterogénesis, el cual se caracteriza por la gradual acumulación de sustancias de reserva denominadas en conjunto vitelo, compuesto por fosfoproteínas, lípidos y glucógeno; los cuales serán utilizados cómo fuente nutricional por el embrión. El proceso de vitelogénesis es regulado por los estrógenos como el 17- $\beta$-estradiol o la estrona, hormonas esteroideas que son sintetizados en las células foliculares. Los estrógenos son transportados a través del torrente sanguíneo hacia el hígado, donde inducen la síntesis y liberación de una glucofosfolipoproteina denominada vitelogenina. Una vez que la vitelogenina es liberada desde el hígado, es transportada por el torrente sanguíneo hacia los folículos ováricos. Llegando a la red de capilares de la teca, la vitelogenina es transportada a una serie de canales los cuales atraviesan entre las células foliculares hasta la superficie del ovocito donde se encuentran unos pozos endociticos, los cuales transportaran a la vitelogenina hacia el interior del ovoplasma por medio de endosomas. En el interior de los endosomas, la vitelogenina es dividida por acción proteolítica en dos compuestos: la lipovitelina y la fosvitina. Conforme estos endosomas van llegando al ovoplasma, comienzan a fusionarse formando las plaquetas vitelinas. El proceso de endocitosis de la vitelogenina es regulado por las gonadotropinas, en este caso por hormonas homólogas tanto estructural cómo funcionalmente a la hormona folículo-estimulante y la hormona luteinizante. (Dumont y Brummett, 1978; Uribe, 2003; Griet et al. 2009; Ogielska y Bartmanska, 2009; Tsai, 2011). La aparición y el engrosamiento gradual en la zona pelúcida en los folículos en crecimiento secundario de $A$. mexicanum indica que hay una mayor actividad de 
comunicación entre el ovocito con las células foliculares, en el caso de las segundas, los cambios morfológicos observados en ellas indica que hay una mayor actividad fisiológica como la producción de estrógenos. A lo largo del crecimiento secundario, la teca de $A$. mexicanum presenta un engrosamiento gradual y mayor vascularización, ésto puede deberse a que el ovocito requiere de más nutrientes para su crecimiento y necesita una mayor área para la captación de los mismos así como de otros compuestos como la vitelogenina, necesaria para el desarrollo de los embriones. De acuerdo con Guraya (1973) y Dumont y Brummett (1978) la teca participa con la difusión de lípidos hacia el folículo y con las células foliculares participa en la producción de hormonas esteroides, siendo que las células de la teca sintetizan andrógenos como la testosterona y células foliculares convierten los andrógenos en estrógenos, indispensables para el mantenimiento de la vitelogénesis. Sin embargo, Norris (1997) señala que las células foliculares son la mayor fuente de hormonas esteroides en anfibios.

Cuando los ovocitos alcanzan su máxima talla comienzan a observarse una serie de cambios morfológicos en los folículos. Los folículos preovulatorios de $A$. mexicanum se caracterizan por presentar una reducción en el grosor de la zona pelúcida y en la altura de las células foliculares, las cuales cambian de una morfología cubica a aplanada. La teca se muestra altamente vascularizada, mientras que el ovoplasma está ocupado en su totalidad por las plaquetas vitelinas, las más grandes se localizan en el polo vegetal mientras que las más pequeñas se encuentran en el polo animal junto con la vesícula germinal y una gran concentración de gránulos pigmentarios. Procesos muy similares han sido descritos en otras especies de anfibios (Dumont, 1972; Sharon et al. 1997; Prado et al. 2004; Oliveira y Santos, 2004; Yartsev et al. 2015; Montezol et al. 2018; Tapia-Guato, 2018). De acuerdo con Grier et al. (2009), Ogielska y Bartmanska (2009) y Uribe (2011) los procesos cómo la maduración de los ovocitos y la ovulación son regulados por la hormona luteinizante, la cual induce la síntesis de progesterona tanto en las células foliculares cómo de la teca y se observa un incremento en los niveles de andrógenos como la testosterona y la 
dihidrotestosterona asi como una caída en los niveles de estradiol. La progesterona en conjunto con los andrógenos participan en la inhibición de la vitelogénesis e inducen cambios en el núcleo y el ovoplasma, modificando su metabolismo y reanudando la meiosis hasta su segundo arresto en la metafase II donde ya pueden ser liberados para su fecundación. La reducción del grosor en la zona pelúcida y en la altura de las células foliculares indica un descenso en la comunicación con el ovocito, que antecede a la futura ovulación.

Una vez que los ovocitos son liberados, los elementos restantes del folículo experimentan algunas modificaciones, convirtiéndose en foliculos postovulatorios. De acuerdo con Guraya (1968), Chieffi y Botte (1970) y Saidapur (1982) los folículos postovulatorios o cuerpos lúteos en anfibios se caracterizan por presentar un lumen, evidencia de la presencia del ovocito, posteriormente se observa un proceso de contracción del folículo hacia el espacio vacío dejado por el ovocito, las células foliculares y la teca comienzan a hipertrofiarse, las células foliculares adquieren la apariencia de una epitelio estratificado debido a la contracción, ocupando el espacio dejado por el ovocito mientras que la teca permanece en la periferia, sin invadir a las células foliculares, sin embargo, adquiere la forma de una capsula fibrosa rica en vasos sanguíneos. Por último, se observa una degeneración de las células foliculares y la reabsorción del folículo. Esto es similar a lo que se observó en los folículos postovulatorios de $A$. mexicanum. Se ha reportado actividad esteroidogénica en los folículos postovulatorios. Grier et al. (2009) señalan que la actividad secretora de los folículos postovulatorios está relacionada con la regulación de la proliferación ovogonial al final del periodo reproductor. Por otro lado, Uribe (2009) señala que pueden estar involucrados con el mantenimiento de las preñez en las especies de salamandras vivíparas, debido a los altos niveles de progesterona durante la gestación, sin embargo, los folículos postovulatorios en especies ovíparas presentan una duración muy breve en el estroma, cómo es el caso de $A$. mexicanum, ya que en el presente estudio solo se reportaron folículos postovulatorios durante el invierno. 
La atresia folicular es un proceso que estuvo presente durante todo el ciclo reproductor de $A$. mexicanum y aunque no es considerada una etapa del ciclo reproductor, algunos autores como Prado et al. (2004) en L. labyrinthicus y Montezol et al. (2018) para R. schneideri la han considerado en sus trabajos como un estadio más del ciclo reproductor. De acuerdo a lo señalado por Saidapur y Nadkarni (1973) y Saidapur (1978), los folículos atrésicos de los anfibios se caracterizan por la pérdida del contorno del folículo, la degeneración de la zona pelúcida, la proliferación e hipertrofia de las células foliculares las cuales comienzan a invadir al ovocito atrésico fagocitándolo, a la par, la teca también comienza a hipertrofiarse, el folículo comienza a contraerse siendo visibles únicamente las células foliculares y de la teca y la gradual aparición de cuerpos pigmentarios. Por último, las células foliculares comienzan a degenerarse y el tejido conjuntivo junto con los cuerpos pigmentarios se reabsorben. Este proceso es muy similar a lo que fue observado en los folículos atrésicos de $A$. mexicanum a lo largo del ciclo anual. Saidapur (1978) sugiere que los folículos atrésicos pueden presentar actividad secretora durante sus estadios más tempranos.

\subsection{Morfología de la cloaca y las glándulas cloacales.}

La cloaca es una estructura que conecta la parte distal del intestino, los conductos de Wolff y los oviductos con el medio externo. De acuerdo con Sever (2003), la cloaca de los urodelos se divide en dos regiones, el conducto cloacal que es una región cilíndrica estrecha y la cámara cloacal, una cavidad mucho más amplia. Esta descripción es muy similar a lo que se observó en la anatomía cloacal de $A$. mexicanum. Se ha reportado que la cloaca de los urodelos se encuentra revestida generalmente por un epitelio pseudoestratificado (Sever, 2003) cómo en A. talpoideum (Trauth, Sever y Semlitsch, 1994) y Bolitoglossa nicefori (González-León y RamírezPinilla, 2011), sin embargo, las descripciones del epitelio cloacal en otras especies de salamandras difieren con esta afirmación. Verrell y Sever (1988) reportaron que la cloaca de Triturus vulgaris esta revestida con un epitelio columnar simple mientras que Brizzi et al. (1989) reportaron un epitelio columnar biestratificado en la cloaca de Salamandrina tergiditata. La cloaca de A. mexicanum presentó un epitelio columnar 
biestratificado, similar a lo reportado con S. tergiditata (Brizzi et al. 1989). En el epitelio cloacal de $A$. mexicanum se observaron tanto células ciliadas cómo células secretoras, cuyas secreciones fueron afines tanto a PAS como a azul alciano. La presencia de cilios ha sido reportada en la mayoría de las familias del orden Urodela, aunque está ausente en algunos integrantes de la familia Salamandridae y aparentemente todas las salamandras de la familia Plethodontidae (Sever, 2003). En S. tergiditata (Brizzi et al. 1989), se observó que las células ciliadas estaban localizadas solamente en el techo cloacal, cercanas a las espermatecas. Esta característica también fue observada en $A$. mexicanum, posiblemente los cilios faciliten la llegada de los espermatozoides hacia la espermateca. La actividad secretora del epitelio cloacal ha sido reportada en otras especies de salamandras. En B. nicefori (González-León y Ramírez-Pinilla, 2011) no se reportaron células secretoras en el epitelio cloacal pero si una reacción positiva a azul alciano. En T. vulgaris (Verrell y Sever, 1988), las actividad secretora de las células presentó una reacción positiva a PAS, lo mismo fue reportado para $S$. tergiditata por Brizzi et al. (1989) quienes además reportaron que el máximo nivel de actividad fue observado en primavera. El epitelio cloacal de $A$. mexicanum presentó actividad secretora durante todo el ciclo anual, con afinidad tanto para azul alciano cómo PAS. Estos colorantes son utilizados para la identificación de carbohidratos de naturaleza ácida y neutra respectivamente. Se desconoce cuál es el papel de estas secreciones pero podrían estar asociadas con la actividad enzimática en algún evento determinado cómo la desintegración del espermatóforo y la liberación de los espermatozoides en el interior de la cloaca.

En la cloaca femenina de los urodelos se ha reportado la presencia de algunas glándulas, en el caso de la familia Ambystomidae se han descrito tres tipos de glándulas: las ventrales, las espermatecas y las dorsales (Sever, 2003).

Las glándulas ventrales de $A$. mexicanum son las más grandes y abundantes dentro de la cloaca las cuales se caracterizan por presentar un epitelio columnar alto con afinidad a PAS. Estas glándulas han sido descritas en todas las especies de urodelos, presentando la morfología antes mencionada y se piensa que participan en 
la secreción de feromonas (Sever, 1992). En A. talpoideum (Trauth et al. 1994) las glándulas ventrales presentan actividad a lo largo del ciclo reproductor pero se observó un pico de actividad entre los meses de noviembre y febrero, por lo que se cree que aparte de la secreción de feromonas, también participa con otro tipo de señales, ya sea de reconocimiento o marcaje. Para $A$. mexicanum no se realizó un análisis de la estacionalidad de las glándulas ventrales en el presente estudio, sin embargo, no se descarta que puedan realizar esa función, ya que el hábitat natural de esta especie son cuerpos de agua con una alta turbiedad, por lo que la visibilidad es reducida y el uso de feromonas es vital para la localización y el cortejo.

La espermateca es la glándula más estudiada en la cloaca femenina de los urodelos. En A. mexicanum, las espermatecas son glándulas localizadas a lo largo de la cloaca y presentan epitelio columnar, similar a lo descrito en otros urodelos (Sever, 2003), salvo en Triturus vulgaris (Sever et al. 1999) en la que se reportó un epitelio cúbico simple. La composición química de las secreciones de la espermateca varía de manera considerable entre las especies. En A. mexicanum, las secreciones de la espermateca presentaron afinidad con PAS. Esto es similar a lo descrito para $T$. vulgaris (Verrell y Sever, 1988), Eurycea cirrigera (Sever, 1991), A. tigrinum (Sever, 1995), Notophthalmus viridescens (Sever et al. 1996) y Rhyacotriton variegatus (Sever et al. 2004). En otras especies de salamandras, las secreciones de la espermateca presentaron afinidad con azul alciano como en A. opacum (Sever y Kloepeer, 1993) y A. talpoideum (Trauth et al. 1994), mientras que otras especies como S. terdigitata (Brizzi et al, 1989) y B. nicefori (González-León y Ramirez-Pinilla, 2011) presentaron afinidad con ambos colorantes. El epitelio de la espermateca de A. tigrinum presentó una leve reacción a azul alciano pero no era significativa (Sever, 1995), mientras que en $A$. opacum (Sever y Kloepeer, 1993) se presentan vacuolas lipídicas en la región basal del epitelio. Un caso particular es el de S. salamandra (Kruczynski, Greven y Passia, 1986), cuya espermateca presenta secreciones ricas en zinc. Se considera que la espermateca es una glándula que participa en el almacenamiento espermático y se sugiere que sus secreciones pueden contribuir en la nutrición de los 
espermatozoides o generando un medio cuya osmolaridad propicie la quiescencia de los espermatozoides (Sever, 2003). La duración del almacenamiento varía entre las especies. En S. salamandra y $S$. atra se ha reportado un periodo de hasta de dos años (Greven y Guex, 1994, Guex y Greven, 1994) y se ha sugerido que la presencia de zinc en las secreciones de la espermateca podría participar en este fenómeno. (Kruczynski et al. 1986; Guex y Greven, 1994). En la mayoría de las especies de urodelos, el tiempo de almacenamiento espermático está relacionado con la duración del periodo de reproducción, el cual puede abarcar entre uno a seis meses y durante este periodo se ha observado que los espermatozoides se encuentran embebidos dentro del epitelio de la espermateca, entre cada célula; se desconoce si esta particularidad está relacionada con su nutrición o si es un proceso de espermiofagia, un proceso de degeneración de los espermatozoides que ha sido reportado dentro de las espermatecas al final del ciclo reproductor (Houck y Schwenk, 1984; Trauth, 1984; Verrell y Sever, 1988; Brizzi et al. 1989; Sever, 1991; Sever et al. 1995; Sever et al. 1996; Sever et al. 1999; Sever et al. 2004; González-León y Ramirez-Pinilla, 2011). Solo en E. cirrigera se ha reportado la supervivencia de los espermatozoides hasta el siguiente ciclo reproductor (Sever, 1991). En el caso de los ambistomidos, Armstrong y Duhon (1989) mencionan que son especies con un almacenamiento espermático de corto plazo, lo cual coincide con lo descrito por Sever (1995) para A. tigrinum y en lo observado en el presente estudio en $A$. mexicanum, ya que solo se observaron espermatozoides en las espermatecas de una hembra tres días después de que esta colectó el espermatóforo. Sin embargo, en otras especies de ambistomidos, se ha registrado la presencia de espermatozoides dentro de la espermateca por un mayor tiempo. En A. talpoideum (Trauth et al. 1994) los espermatozoides estuvieron presentes durante cinco meses seguidos, mientras que en $A$. opacum (Sever y Kloepeer, 1993; Sever et al. 1995) se observaron espermatozoides durante seis meses, en los dos primeros meses se describieron espermatozoides íntegros dentro de la espermateca mientras que en los cuatro meses restantes se observaron evidencias de degradación de los espermatozoides, de los cuales ninguno sobrevivió al siguiente ciclo reproductor. Posiblemente el ciclo de vida de cada especie pueda ser 
un factor que tenga relación con el tiempo de almacenamiento espermático. $A$. mexicanum es considerado como neoténico obligado, lo que significa que retiene características juveniles durante todo su ciclo de vida, siendo capaz de reproducirse en su estado larvario sin necesidad de alcanza la madurez en el medio acuático, idóneo para el desarrollo de las crías (Majchrzak, 2004), por el contrario, A. opacum es una salamandra no neoténica la cual se reproduce en el medio terrestre, dejando sus huevos en estanques secos en espera de las inundaciones (Rogers, 2000). Considerando lo anterior, es probable que las presiones del medio en los que habita cada especie hayan influido con su ciclo de vida y por lo tanto, con el tiempo de almacenamiento espermático. Lo anterior igualmente aplicaría para $A$. talpoideum y $A$. tigrinum, dos especies que, aunque presentan neotenia facultativa, es decir, que pueden permanecer en estado larvario siendo capaces de reproducirse pero que, por algún cambio o presión en su medio, son capaces de terminar la metamorfosis y sobrevivir en el medio terrestre (Wakahara, 1996; Wentz, 2001; Behr, 2009), presentan tiempos de almacenamiento muy diferentes, siendo que $A$. talpoideum puede almacenar espermatozoides hasta cinco meses mientras que $A$. tigrinum solo por unos días (Trauth et al. 1994; Sever, 1995). Se podría considerar que la capacidad de almacenamiento está relacionada con el grado de desarrollo de las glándulas entre un ejemplar neoténico y uno que ha pasado por la metamorfosis, no obstante, Licht y Sever (1991) compararon la anatomía cloacal de ejemplares larvarios y ejemplares metamorfoseados de $A$. gracile, otra salamandra con neotenia facultativa, y no encontraron diferencias considerables entre ambas etapas, por lo que no es un factor que se pueda considerar como relevante. Hardy y Dent (1987) reportaron que la prostaglandina F2 $\alpha$ participa en la liberación de los espermatozoides de la espermateca, esto puede ser sustentado con el reporte de Sever y Kloepeer 1993) quienes reportaron la liberación de secreciones lipídicas en la región basal del epitelio de la espermateca hacia la membrana basal y las células mioepiteliales, las cuales probablemente participen con la señalización de funciones cómo la contracción de las células mioepiteliales. Aunque no se reportó la presencia de estas secreciones en la espermateca de $A$. mexicanum, no se descarta que puedan estar presentes. Una vez 
que los espermatozoides son liberados de las espermatecas, estos se desplazan hasta encontrarse con los ovocitos entre la parte final del oviducto y la cloaca (Greven, 2003; Watanabe y Onitake, 2003). Se ha reportado lo que se denomina polispermia fisiológica, es decir, que varios espermatozoides logran fecundar a un mismo ovocito, sin embargo, pocos espermatozoides logran cruzar las cubiertas gelatinosas que se forman durante el trayecto del ovocito por el oviducto y se desconoce cuál de los espermatozoides que lograron atravesar las cubiertas participara en la fecundación (Charbonneau et al. 1983; Bordzilovskaya y Dettlaff, 1991; Greven, 2003; Watanabe y Onitake, 2003).

Las glándulas dorsales son las menos conocidas de las tres y cómo su nombre lo indica, estas se localizan en la pared dorsal de la cloaca (Sever, 2003). Trauth et al. (1994) reportaron que en $A$. talpoideum las glándulas dorsales se localizan en la parte posterior de la cloaca y presentan una reacción positiva a PAS, mientras que en A. mexicanum, las glándulas dorsales se encuentran en la parte anterior de la cloaca y presentan reacción positiva a azul alciano. De acuerdo con Sever (2003), las glándulas dorsales pueden localizarse de manera cefálica o caudal a las espermatecas y aunque presentan una morfología similar, se caracterizan por presentar menor tamaño y una unidad secretora muy reducida. En el caso de $A$. mexicanum, las glándulas dorsales están constituidas por estructuras túbulo-alveolares pequeñas conectadas a un solo conducto. Se desconoce cuál sea su función pero se ha reportado la presencia de espermatozoides en su interior (Trauth et al. 1994), por lo que se pueden considerar cómo espermatecas con un menor grado de desarrollo, espermatecas que ya habían liberado su contenido de espermatozoides o estructuras glandulares vestigiales que están en algún proceso evolutivo de regresión.

\subsection{Cambios estacionales durante el ciclo anual.}

Es posible determinar el periodo de reproducción de una especie mediante el análisis de las variaciones morfológicas de su aparato reproductor. En A. mexicanum se observó un aumento gradual en la longitud de los ovarios durante el periodo de 
estudio. Esto sería algo inusual en los individuos de vida libre. Probablemente esto se deba a que los organismos utilizados estaban en condiciones de cautiverio con alimento disponible y con muy pocas presiones. Aunque la ovogénesis es un proceso metabólicamente costoso, la disponibilidad de alimento durante todo el ciclo y la ausencia de presiones ambientales pudieron haber facilitado que los organismos mantuvieran el aumento de talla de los ovarios durante todo el ciclo. En vida libre, las variaciones en la talla de los órganos sexuales son mucho más notorias. En $S$. keyserlingii (Yartsev y Kuranova, 2015; Bulakhova y Berman, 2017) el periodo de reproducción inicia durante el otoño, pudiéndose apreciar el desarrollo de los ovarios y oviductos, proceso que se interrumpe durante el invierno y se reanuda en la primavera, donde se observa la máxima talla del sistema reproductor, posteriormente, terminando la primavera, se observa regresión del aparato reproductor, con un decremento de tamaño considerable tanto en los ovarios cómo en los oviductos. Aunque la longitud de los ovarios de $A$. mexicanum parecía aumentar durante todo el ciclo reproductor, la proporción de los folículos ováricos presentó una dinámica diferente. La proporción de folículos en crecimiento primario se mantuvo relativamente constante durante todo el ciclo salvo en primavera donde se observó un ligero aumento, el resto de los folículos reportados presentaron variaciones más marcadas. Entre el verano y el otoño se observó un incremento en la proporción de los folículos en crecimiento secundario pero a partir del invierno se observó un ligero decremento que fue mucho más marcado durante la primavera. Los folículos preovulatorios por su parte, presentaron un aumento gradual en su proporción numérica a lo largo del ciclo reproductor mientras que la atresia tuvo una presencia marcada durante las estaciones de verano y primavera, sin embargo, la tasa de atresia fue reducida durante las estaciones de otoño e invierno. Con estos datos se puede inferir que el periodo de actividad ovárica abarca desde julio hasta enero, siendo el mes de octubre el de mayor actividad. Posteriormente, se observó un aumento en la atresia y una disminución de los folículos en crecimiento secundario, sin embargo, en el mes de abril se registró un ligero incremento en la proporción de folículos en crecimiento primario, por lo que es probable que el periodo de regresión abarque de febrero a marzo y que la proliferación 
de folículos en crecimiento primario tenga lugar a partir de abril y mayo. De acuerdo con Grier et al. (2009), la proliferación de ovogonias presenta una relación con la actividad de los folículos postovulatorios, los cuales solo están presentes en el ovario de A. mexicanum durante enero, por lo tanto, la proliferación de ovogonias posiblemente sea más activa durante el periodo en el que ocurre la ovulación. Con respecto a la diferenciación de los ovocitos primarios y la foliculogénesis, Calatayud, Stoops y Durrant (2018) mencionan que estos procesos presentan regulación autonómica, independiente de los factores ambientales. En los anuros se ha reportado que la actividad reproductora presenta una relación inversa con los niveles de melatonina y las bajas temperaturas (Calatayud et al. 2018). En R. schneideri (Montezol et al. 2018) el análisis de la variación en las proporciones de folículos ováricos durante cada mes permitió conocer que el periodo de reproducción de $R$. schneideri está en sincronía con el periodo de lluvias. Por lo tanto, el ciclo reproductor de los anuros presenta una relación directa con un fotoperiodo largo, temperaturas cálidas y las precipitaciones, siendo el momento idóneo para la oviposición. Los urodelos por el contrario, presentan ciclos reproductores asociados a fotoperiodos cortos y bajas temperaturas (Sever et al. 1995; Yartsev y Kuranova, 2015), esto podría indicar que a la inversa de lo que ocurre con los anuros, los urodelos responden positivamente a una mayor duración en la secreción de melatonina. En S. keyserlingii, Bulakhova y Berman (2017) reportaron que la actividad reproductora inicia durante el otoño, época donde el fotoperiodo se reduce y la temperatura desciende, sin embargo, también hay una sincronía con el periodo de precipitaciones. Mena-Gonzalez y ServinSamora (2014) mencionan que el periodo de reproducción de $A$. mexicanum está asociado con bajas temperaturas y un fotoperiodo corto, lo cual coincide con lo reportado en el presente estudio, ya que el crecimiento secundario o vitelogénesis se hace más marcado durante octubre, una época donde el fotoperiodo comienza a reducirse y las temperaturas bajan.

Se ha reportado que la actividad de la espermateca está en relación directa a la del ovario, siendo que durante le época de reproducción, el epitelio de la espermateca 
presenta variaciones morfológicas pasando de un epitelio cúbico a uno columnar con actividad secretora bien definida la cual concluye al final del periodo reproductor (Verrell y Sever, 1988; Trauth et al. 1994; Brizzi et al. 1995; Sever et al. 1995; Sever et al. 1996.) González-León y Ramirez-Pinilla (2011) reportaron que la actividad secretora de la espermateca de $B$. nicefori varía de acuerdo a los estadios de ovogénesis, durante la previtelogénesis, se presentaba una afinidad hacia azul alciano pero que una vez iniciada la vitelogénesis el epitelio comenzó a presentar también una afinidad con PAS. En E. cirrigera (Sever, 1991; Sever y Brunette, 1993) algo similar ocurre, ya que el inicio y la duración de la actividad secretora de la espermateca está directamente relacionada con la duración de la vitelogénesis, por lo que es probable que los estrógenos y progestágenos tengan un papel importante en la regulación de la actividad de la espermateca. Sin embargo, la espermateca de $A$. mexicanum no presentó variaciones morfológicas a lo largo del ciclo reproductor; esto puede ser en consecuencia al estado de cautiverio y a la presencia constante de folículos ováricos con actividad secretora como los folículos en crecimiento secundario o vitelogénicos y los folículos preovulatorios. 


\section{CONCLUSIÓN}

Los ovarios de $A$. mexicanum presentaron una morfología similar a la que ha sido descrita en otras especies de urodelos.

De igual forma, la ovogénesis presento similitudes a lo descrito tanto en otros urodelos como en anuros y en peces.

La cloaca de $A$. mexicanum presentó morfología similar a la descrita en otras especies de urodelos, sin embargo, la morfología del epitelio de revestimiento difiere de lo reportado en otras especies de ambistomidos.

Se encontraron tres grupos de glándulas túbulo-alveolares dentro la cloaca: dorsales, ventrales y la espermateca.

No se observaron diferencias significativas entre la longitud del ovario a lo largo del ciclo anual, sin embargo, se observaron variaciones significativas en la proporción de los folículos ováricos, por los que se puede inferir que la el ciclo reproductor de las hembras inicia desde el verano (julio) y concluye iniciando la primavera (marzo).

No se observaron diferencias significativas en el diámetro de la espermateca o en la morfología de su epitelio a lo largo del ciclo anual. 


\section{LITERATURA CITADA}

Aguilar-Miguel, X. y Casas Andreu, G (2005). Ficha técnica de Ambystoma mexicanum. En: Aguilar-Miguel, X. (Eds). Algunas especies de anfibios y reptiles contenidos en el Proyecto de Norma Oficial Mexicana PROY-NOM-059-ECOL2000. Facultad de Ciencias, Centro de Investigación en Recursos Bióticos, Universidad Autónoma del Estado de México. Bases de datos SNIB-CONABIO. Proyecto No. W035. México, D.F.

Armstrong J. B. \& Duhon S. T. (1989). Induced spawnings, artificial insemination, and other genetic manipulations. In: Armstrong JB, Malacinski GM, editors. Developmental Biology of the Axolotl (pp. 228-235). New York, USA: Oxford University Press.

Baitchman, E. J., \& Herman, T. A. (2014). Caudata (Urodela): Tailed Amphibians. Fowler's Zoo and Wild Animal Medicine, Volume 8-E-Book, 8, 13.

Barrett, K. \& Guyer, C. (2008). Differential responses of amphibians and reptiles in riparian and stream habitats to land uses disturbances in western Georgia, USA. Biological conservation 141: 2290-2300.

Beebee, T. J. C. y Griffiths, R. A. (2005) The amphibian decline crisis: A watershed for conservation biology? Biological Conservation 125: 271-285.

Beesley, S. G., Costanzo, J. P. y Lee, R. E. (1998) Cryopreservation of Spermatozoa from Freeze-Tolerant and -Intolerant Anurans. Cryobiology 37: 155-162.

Behr, A. 2009. "Ambystoma talpoideum" (On-line), Animal Diversity Web. Recuperado de: https://animaldiversity.org/accounts/Ambystoma talpoideum/

Bordzilovskaya, N. P., \& Dettlaff, T. A. (1991). The axolotl Ambystoma mexicanum. In Animal Species for Developmental Studies (pp. 203-230). EUA: Springer. 
Brizzi, R., Delfino, G., \& Calloni, C. (1989). Female Cloacal Anatomy in the Spectacled Salamander, Salamandrina terdigitata (Amphibia: Salamandridae). Herpetologica, 45(3): 310-322.

Brizzi, R., Delfino, G., Selmi, M. G., \& Sever, D. M. (1995). Spermathecae of Salamandrina terdigitata (Amphibia: Salamandridae): Patterns of sperm storage and degradation. Journal of Morphology, 223(1): 21-33. https://doi.org/10.1002/jmor.1052230105

Browne, R. K, Li, H., Robertson, H., Uteshev, V. K., Shishova, N. V., McGinnity, D., Nofs, S., Figiel, C. R., Mansour, N., Lloyd, R. E., Agnew, D., Carleton, C. R., Wu, M., y Gakhova, E. N. (2011). Reptile and amphibian conservation through gene banking and other reproduction technologies. Russian Journal of Herpetology 18: 165-174.

Browne, R. K., Clulow, J. y Mahony, M. (2002). The short-term storage and cryopreservation of spermatozoa from hylid and myobatrachid frogs. CryoLetters 23: 129-136.

Browne, R. K., Clulow, J., Mahony, M. y Clark, A. (1998) Successful Recovery of Motility and Fertility of Cryopreserved Cane Toad (Bufo marinus) Sperm. Cryobiology 37: 339-345.

Bulakhova, N. A., \& Berman, D. I. (2017). Reproductive Cycle of Females and Reproduction of the Siberian Salamander (Salamandrella keyserlingii, Caudata, Hynobiidae) on the Coast of the Sea of Okhotsk. Biology Bulletin, 44(7): 688-699. DOI: $10.1134 / \mathrm{S} 1062359017070068$

Carroll, E. J., Palmer, R. \& Ruibal, R. (1992). Structure and Macromolecular Composition of the Jelly Coats of the Urodele Ambystoma mexicanum. Development, Growth \& Differentiation, 34 (5): 501-508. 
Calatayud, N. E., Stoops, M., \& Durrant, B. S. (2018). Ovarian control and monitoring in amphibians. Theriogenology, 109: https://doi.org/10.1016/j.theriogenology.2017.12.005

Charbonneau, M., Moreau, M., Picheral, B., Vilain, J. P., \& Guerrier, P. (1983). Fertilization of amphibian eggs: a comparison of electrical responses between anurans and urodeles. Developmental biology, 98(2): 304-318.

Chieffi, G., \& Botte, V. (1970). The Problem of «Luteogenesis» in Non-Mammalian Vertebrates. Italian Journal of Zoology, 37(2): 85-102. DOI:10.1080/11250007009438669

CONABIO (2011). Fichas de especies prioritarias. Ajolote mexicano (Ambystoma mexicanum). Comisión Nacional de Áreas Naturales Protegidas y Comisión Nacional para el Conocimiento y Uso de la Biodiversidad, México D.F.

Cushman, S. A. (2006) Effects of habitats loss and fragmentation on amphibians: A reviews and prospectus. Biological conservation 128, 231.240.

Dumont, J. N. (1972). Oogenesis in Xenopus laevis (Daudin). I. Stages of oocyte development in laboratory maintained animals. Journal of morphology, 136(2), 153-179.

Dumont, J. N., \& Brummett, A. R. (1978). Oogenesis in Xenopus laevis (Daudin). V. Relationships between developing oocytes and their investing follicular tissues. Journal of morphology, 155(1), 73-97.

Endo, T., Bryant, S. V., \& Gardiner, D. M. (2004). A stepwise model system for limb regeneration. Developmental biology, 270(1), 135-145.

Ferreira, A., Silva, D. N., Van Sluys, M. \& Dolder, H. (2009). Seasonal changes in testicular and epididymal histology of the tropical lizard, Tropidurus itambere (Rodrigues, 1987) during its reproductive cycle. Brazilian Journal of Biology 69 (2): 429-435. 
Grier, H. J., Uribe, M. C., \& Patino, R. (2009). The ovary, folliculogenesis, and oogenesis in teleosts. In: Barrie G. M. J. Eds). Reproductive biology and phylogeny of fishes (agnathans and bony fishes). Vol. 8A (pp. 25-84).New Hampshire. EUA: Science Publishers.

Greven, H. (2002). The urodele oviduct and its secretions in and after G. von Wahlert's doctoral thesis "Eileiter, Laich und Kloake der Salamandriden". Bonner zoologische Monographien, 50, 25-61.

Greven, H. (2003). Chapter 5. Oviduct and egg-jelly. In: D. Sever. Reproductive biology and phylogeny of Urodela. Science Publishers. Inc.

Greven, H. \& Guex, G. D. (1994). Structural and physiological aspects of viviparity in Salamandra salamandra. Mertensiella, 4, 139-160.

Guex, G. D., \& Greven, H. (1994). Structural and physiological aspects of viviparity in Salamandra atra. Mertensiella, 4, 161-208.

González-León, E., \& Ramírez-Pinilla, M. P. (2011). Cloacal morphology in Bolitoglossa nicefori (Caudata: Plethodontidae): variation during the reproductive cycle. The Anatomical Record, 294(2), 349-362.

Guraya, S. S. (1968). Histochemical study of granulosa (follicular) cells in the preovulatory and postovulatory follicles of amphibian ovary. General and comparative endocrinology, 10(1), 138-146.

Guraya, S. S. (1973). Morphology, histochemistry and biochemistry of follicular growth and atresia. In Annales de Biologie Animale Biochimie Biophysique 13. 229-245. EDP Sciences.

Hardy, M. P., \& Dent, J. N. (1987). Hormonal facilitation in the release of sperm from the spermatheca of the red-spotted newt. Experientia, 43(3), 302-304.

Harmer, A. J. y Mcdonnell, M. J. (2008) Amphibian ecology and conservation in the urbanising world: A review. Biological Conservation 141: 2432-2449. 
Holt, W. V., Abaigar, T., Watson, P. F. y Wildt, D. E. (2003). Genetic resource banks for species conservation. In: Wiliam V. H., Amanda R. P., John R. \& David E. W. (Eds). Reproductive Science and Integrated Conservation (pp. 267-280) Londres, Reino Unido: Cambridge University Press.

Howard, J., Marinari, P., E \& Wildt, D. E. (2003). Black-footed ferret: model for assisted reproductive technologies contributing to in situ conservation. In: Wiliam V. H., Amanda R. P., John R. \& David E. W. (Eds). Reproductive Science and Integrated Conservation (pp. 249-266) Londres, Reino Unido: Cambridge University Press.

Humason, G.L. (1979). Animal tissue techniques (4 ${ }^{a}$ Ed.). San Francisco, EUA: W.H. Freeman and Company.

Houck, L. D., \& Schwenk, K. (1984). The potential for long-term sperm competition in a plethodontid salamander. Herpetologica, 40(4), 410-415.

Kouba, A. J., Lloyd, R. E., Houck, M. L., Silla, A. J., Calatayud, N., Trudeau, V. L., Clulow, J., Monilia, F., Langhorne, C., Vance, Carrie, Arregui, L., Germano, J., Lermen, D. \& Della-Togna, G. (2013). Emerging trends for biobanking amphibian genetic resources: The hope, reality and challenges for the next decade. Biological Conservation (164): 10-21.

Kuoba, A. J., Vance, C. K. \& Willis, E. L. (2009). Artificial fertilization for amphibian conservation: Current knowledge and future considerations. Theriogenology 71 : 214-227.

Kruczynski, D., Greven, H., \& Passia, D. (1986). Histochemical demonstration of zinc in the spermatotheka of Salamandra salamandra (L.)(Amphibia, Urodela). Acta histochemica, 79(2), 181-186.

Licht, L. E., \& Sever, D. M. (1991). Cloacal anatomy of metamorphosed and neotenic salamanders. Canadian journal of zoology, 69(8), 2230-2233.

Luna, G.L. (1973). Manual of Histologist staining methods of the Armed Forces. Institute of Pathology. Nueva York, EUA: McGraw-Hill. 
Majchrzak, A. 2004. "Ambystoma mexicanum" (On-line), Animal Diversity Web. Recuperado de: https://animaldiversity.org/accounts/Ambystoma mexicanum/

Mansour, N., Lahnsteiner, F. \& Patzner, R. A. (2011). Collection of gametes from live axolotl, Ambystoma mexicanum and standardization of in vitro fertilization. Theriogenology 75: 354-361.

Mena-González y Servín-Zamora, E. (2014) Manual básico para el cuidado en cautiverio del axolote de Xochimilco (Ambystoma mexicanum). México. Universidad Nacional Autónoma de México.

Mendoza-Cruz, E., Moreno-Mendoza, N., Zambrano, L., \& Villagrán-SantaCruz, M. (2017). Development and gonadal sex differentiation in the neotenic urodele: Ambystoma mexicanum. Zoomorphology, 136(4), 497-509.

Montezol, M., Cassel, M., Silva, D., Ferreira, A., \& Mehanna, M. (2018). Gametogenesis and reproductive dynamics of Rhinella schneideri (Anura: Bufonidae): Influence of environmental and anthropogenic factors. Acta Zoologica, 99(1), 93-104. DOI: 10.1111/azo.12195

Nom, N. O. M. (2010). 059-SEMARNAT-2010. Protección ambiental-Especies nativas de México de flora y fauna silvestres-Categorías de riesgo y especificaciones para su inclusión, exclusión o cambio-Lista de especies en riesgo, 30.

Norris, D, O, (1997). Vertebrade endocrinology. Third edition. EUA: Academic Press.

Ogielska, M. \& Bartmanska (2009). Oogenesis and female reproductive system in amphibia-Anura. In: M. Ogielska. Reproduction in amphibians (pp. 253-272). Florida, EUA: CRC Press.

Oliveira, C. D., \& Santos, L. R. D. S. (2004). Histological characterization of cellular types during Scinax fuscovarius oogenesis (Lutz) (Anura, Hylidae). Revista Brasileira de Zoologia, 21(4), 919-923. 
Park, D., McGuire, J. M., Majchrzak, A. L., Ziobro, J. M., \& Eisthen, H. L. (2004). Discrimination of conspecific sex and reproductive condition using chemical cues in axolotls (Ambystoma mexicanum). Journal of Comparative Physiology A, 190(5), 415-427.

Parra-Olea, G., Flores-Villela, O. y Mendoza-Almeralla, C. (2014). Biodiversidad de anfibios en México. Revista mexicana de biodiversidad 85. 460-466.

Prado, C. P. D. A., Abdalla, F. C., Silva, A. P. Z., \& Zina, J. (2004). Late gametogenesis in Leptodactylus labyrinthicus (Amphibia, Anura, Leptodactylidae) and some ecological considerations. Brazilian Journal of Morphological Sciences 2. 177184.

Proaño-Olmos, B. E. (2013, octubre 7) Fertilización in-vitro con espermatozoides criopreservados de la especie Rhinella marina e identificación de malformaciones en los embriones obtenidos. Tesis de Licenciatura. Escuela de Ciencias Biológicas. Facultad de Ciencias Exactas y Naturales. Pontificia Universidad Católica del Ecuador. Quito, Ecuador.

Rawson, D. M., G. McGregor Reid, G. y Lloyd, R. E. (2011). Conservation rationale, research applications and techniques in the cryopreservation of lower vertebrate biodiversity from marine and freshwater environments. International Zoo Yearbook 45: 108-123. DOI:10.1111/j.1748-1090.2010.00129.x.

Rogers, G. 2000. "Ambystoma opacum" (On-line), Animal Diversity Web. Recuperado de: https://animaldiversity.org/accounts/Ambystoma opacum/

Roldán, E. R. S. y Garde, J. J. (2004) Capitulo 14: Biotecnología de la reproducción y conservación de especies en peligro de extinción. En: M. Gomendio-Kindelán (Ed). Los retos medioambientales del siglo XXI: la conservación de la biodiversidad en España (pp. 307-338). España. Fundación BBVA.

Saidapur, S. K. (1978). Follicular atresia in the ovaries of nonmammalian vertebrates. International review of cytology (54). 225-244. Academic Press. 
Saidapur, S. K. (1982). Structure and function of postovulatory follicles (corpora lutea) in the ovaries of nonmammalian vertebrates. International review of cytology 75 . 243-285. Academic Press.

Saidapur, S. K., \& Nadkarni, V. B. (1973). Follicular atresia in the ovary of the frog Rana cyanophlyctis (Schneider). Acta anat. 1(6): 559-564.

Satoh, A., Graham, G. M. C., Bryant, S. V., \& Gardiner, D. M. (2008). Neurotrophic regulation of epidermal dedifferentiation during wound healing and limb regeneration in the axolotl (Ambystoma mexicanum). Developmental biology, 319(2), 321-335.

Servín-Zamora, E. (2011, marzo 17). Manual del mantenimiento en cautiverio y medicina veterinaria aplicada al ajolote de Xochimilco (Ambystoma mexicanum) en el zoológico de Chapultepec. (Tesis de pregrado). Universidad Nacional Autónoma de México. México, D. F.

Sever, D. M. (1991). Sperm storage and degradation in the spermathecae of the salamander Eurycea cirrigera. Journal of morphology, 210(1), 71-84.

Sever, D. M. (1992). Comparative anatomy and phylogeny of the cloacae of salamanders (Amphibia: Caudata). VI. Ambystomatidae and Dicamptodontidae. Journal of Morphology, 212(3), 305-322.

Sever, D. M. (1995). Spermathecae of Ambystoma tigrinum (Amphibia: Caudata): Development and a Role for the Secretions. Journal of Herpetology, 29(2), 243255. https://doi.org/10.2307/1564561.

Sever, D. (2003) Chapter 9. Courtship and Mating glands. In: D. Sever. Reproductive biology and phylogeny of Urodela (pp. 323-382) New Hampshire, EUA: Science Publishers. Inc.

Sever, D. M., \& Brunette, N. S. (1993). Regionalization of eccrine and spermiophagic activity in spermathecae of the salamander Eurycea cirrigera (Amphibia: Plethodontidae). Journal of morphology, 217(2), 161-170. 
Sever, D. M., Halliday, T., Waights, V., Brown, J., Davies, H. A., \& Moriarty, E. C. (1999). Sperm storage in females of the smooth newt (Triturus $v$. vulgaris L.): I. Ultrastructure of the spermathecae during the breeding season. The Journal of Experimental Zoology, 283(1), 51-70.

Sever, D. M., \& Kloepeer, N. M. (1993). Spermathecal cytology of Ambystoma opacum (Amphibia: Ambystomatidae) and the phylogeny of sperm storage organs in female salamanders. Journal of Morphology, 217(1), 115-127. https://doi.org/10.1002/jmor.1052170110.

Sever, D. M., Krenz, J. D., Johnson, K. M., \& Rania, L. C. (1995). Morphology and evolutionary implications of the annual cycle of secretion and sperm storage in spermathecae of the salamander Ambystoma opacum (Amphibia: Ambystomatidae). Journal of Morphology, 223(1), 35-46.

Sever, D. M., Rania, L. C., \& Krenz, J. D. (1996). Annual cycle of sperm storage in spermathecae of the red-spotted newt, Notophthalmus viridescens (Amphibia: Salamandridae). Journal of Morphology, 227(2), 155-170. https://doi.org/10.1002/(SICI)1097-4687(199602)227:2<155::AID JMOR3>3.0.CO; 2-8.

Sever, D. M., Tait, C. K., Diller, L. V., \& Burkholder, L. (2004). Ultrastructure of the annual cycle of female sperm storage in spermathecae of the torrent salamander, Rhyacotriton variegatus (Amphibia: Rhyacotritonidae). Journal of Morphology, 261(1), 1-17. https://doi.org/10.1002/jmor.10149.

Schreckenberg, G. M., \& Jacobson, A. G. (1975). Normal stages of development of the axolotl, Ambystoma mexicanum. Developmental biology, 42(2), 391-399.

Sharon, R., Degani, G., \& Warburg, M. R. (1997). Oogenesis and the ovarian cycle in Salamandra salamandra infraimmaculata Mertens (Amphibia; Urodela; Salamandridae) in fringe areas of the taxon's distribution. Journal of morphology, 231(2), 149-160. 
Shishova, N. R., Uteshev, V. K., Kaurova, S. A., Browne, R. K. y Gakhova, E. N. (2011). Cryopreservation of hormonally induced sperm for the conservation of threatened amphibians with Rana temporaria as a model research species. Theriogenology (75): 220-232.

Tank, P. W., Carlson, B. M., \& Connelly, T. G. (1976). A staging system for forelimb regeneration in the axolotl, Ambystoma mexicanum. Journal of morphology, 150(1), 117-128.

Tapia Guato, S. A. (2018,febrero, 28). Descripción morfológica parcial de la oogénesis de Bolitoglossa peruviana (Caudata, Plethodontidae) (Tesis de pregrado). Escuela de Ciencias Biológicas. Facultad de Ciencias Exactas y Naturales. Pontificia Universidad Católica del Ecuador. Quito, Ecuador.

Temple-Smith, P. D. (2003). Integrating reproductive sciences into recovery programmes for declining and extinct marsupial populations. In: W. V. Holt, A. R. Pickard. J. R. \& D. E. Wildt (Eds). Reproductive Science and Integrated Conservation (pp. 211-231) Londres, Reino Unido: Cambridge University Press.

Trauth, S. E. (1984). Spermathecal anatomy and the onset of mating in the slimy salamander (Plethodon glutinosus) in Alabama. Herpetologica, 314-321.

Trauth, S. E., Sever, D. M., \& Semlitsch, R. D. (1994). Cloacal anatomy of paedomorphic female Ambystoma talpoideum (Caudata: Ambystomatidae), with comments on intermorph mating and sperm storage. Canadian journal of zoology, 72(12), 2147-2157.

Tsai, P.S. (2011). Chapter 2: Neuroendocrine Control of Reproduction in Amphibians. In: D. O. Norris \& K. H. Lopez. Hormones and Reproduction of Vertebrates. Volume 2: Amphibians (pp.21-38). Londres, Reino Unido: Academic Press.

Uribe, M. C. (2003) Chapter 4. The Ovary and Oogenesis. In: D. Sever (Eds). Reproductive Biology and Philogeny of Urodela (pp. 135-150). New Hampshire, EUA: Science publishers. 
Uribe, M. C. (2009). Oogenesis and Female Reproductive System in AmphibiaUrodela. In: M. Olgielska (Eds). Reproduction of amphibians (pp. 273-304). United States of America. Science Publishers.

Uribe, M. C. (2011). Chapter 4: Hormones and the Female Reproductive System of Amphibians. In: D. O. Norris \& K. H. Lopez. Hormones and Reproduction of Vertebrates. Volume 2: Amphibians (pp. 55-82). Londres, Reino Unido: Academic Press.

Uribe, M.C., Hernández-Franyutti, A. A., Sanz-Ochotorena, A. y González-Porter, G. (2010). Estructura comparada de los folículos ováricos en reptiles. En F. R. Méndez de la Cruz y F. Méndez Sánchez, (Ed.) Reproducción en reptiles. Morfología, ecología y evolución (pp.169-201). México: Universidad Autónoma del Estado de México.

Uribe, M. C. A., Mena, L. F., Carrubba, M. R. C., Estrada, E. F., Palmer, B. D., \& Guillette Jr, L. J. (1989). Oviductal histology of the urodele, Ambystoma mexicanum. Journal of herpetology 23(3). 230-237.

Verrell, P. A., \& Sever, D. M. (1988). The cloaca and spermatheca of the female smooth newt, Triturus vulgaris L. (Amphibia: Urodela: Salamandridae). Acta Zoologica, 69(2), 65-70.

Wakahara, M. (1996). Heterochrony and neotenic salamanders: possible clues for understanding the animal development and evolution. Zoological science, 13(6), 765-777. https://doi.org/10.2108/zsj.13.765

Watanabe, A y Onitake, K. (2003) Chapter 11. Sperm activation. In: D. Sever. Reproductive biology and phylogeny of Urodela (pp.425-446). New Hampshire, EUA: Science Publishers. Inc.

Wentz, A. 2001. "Ambystoma tigrinum" (On-line), Animal Diversity Web. Recuperado de: https://animaldiversity.org/accounts/Ambystoma tigrinum/ 
Yartsev, V. V., Exbrayat, J. M., \& Kuranova, V. N. (2015). Oogenesis in the Siberian salamander, Salamandrella keyserlingii (Amphibia: Caudata, Hynobiidae). Vestn. Tomsk. Gos. Univ. Biol, (4), 127-144. doi: 10.17223/19988591/32/7.

Yartsev, V. V., \& Kuranova, V. N. (2015). Seasonal dynamics of male and female reproductive systems in the Siberian Salamander, Salamandrella keyserlingii (Caudata, Hynobiidae). Asian Herpetological Research 2015, 6(3): 169-183. DOI: 10.16373/j.cnki.ahr.140033

Zambrano, L., Mosig-Reidl, P., McKay, J., Griffiths, R., Shaffer, B., Flores-Villela, O., Parra-Olea, G. \& Wake D. (2010). Ambystoma mexicanum. The IUCN Red List of Threatened Species 2010: e.T1095A3229615. http://dx.doi.org/10.2305/IUCN.UK.20102.RLTS.T1095A3229615.en.

Zambrano González, L., Reynoso, V. H. y G. Herrera. 2003. Abundancia y estructura poblacional del axolotl (Ambystoma mexicanum) en los sistemas dulceacuícolas de Xochimilco y Chalco. Universidad Nacional Autónoma de México. Instituto de Biología. Informe final SNIBCONABIO proyecto No. AS004. México D. F. 
Estudjo circanual de 100 Cambios morfologioos y

euncionales det ovarloy 10

espertateca det lyrodelo

Anbystorita mexidanum:

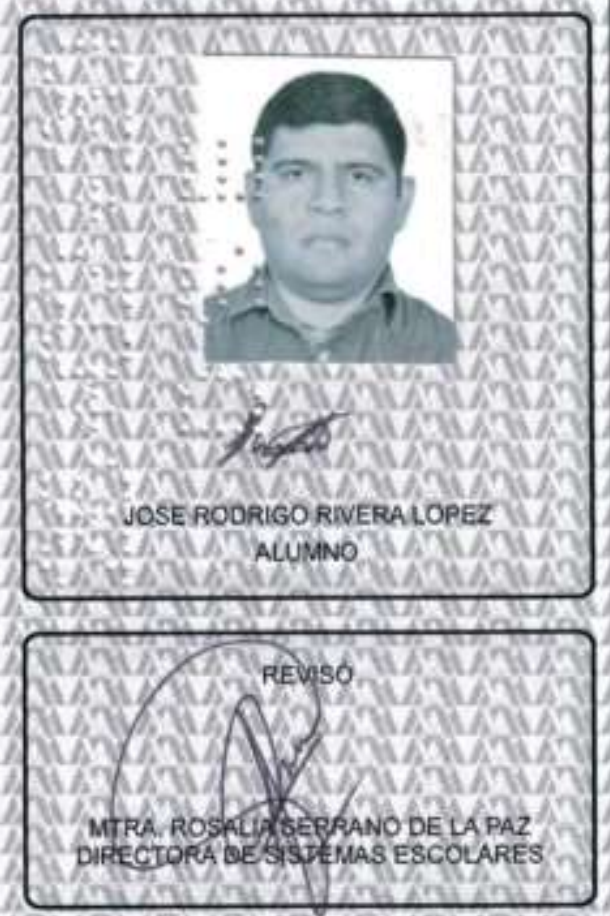

DIRECTORA DE LADIYSIONDECBS

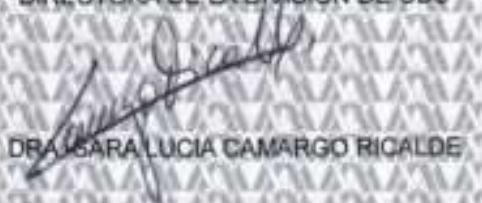

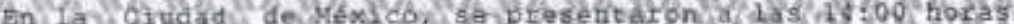

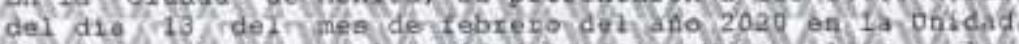

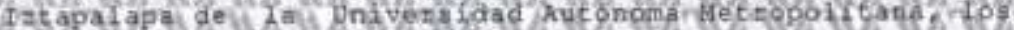
pusgritos miembros del jur gad

DR: MAREO/GARCZA DOREIUZAYA

DRA KARLA PELET BERRANO

DRA WI MARIA DEL ROSARIO TRRRAGOICASTMULANOS

DRA MAEIA DEL CAPMEN QQ IAE ARAMGABAT

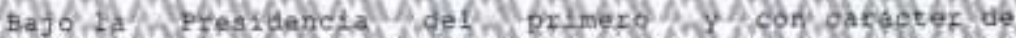

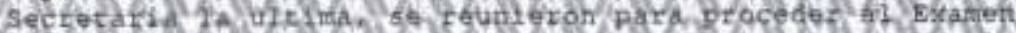

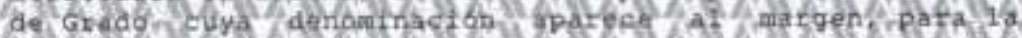

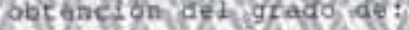

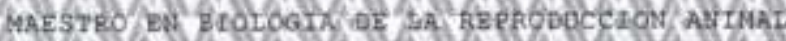

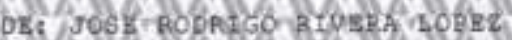

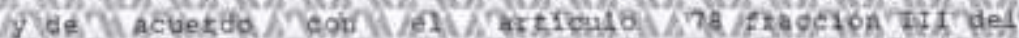

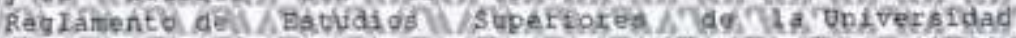

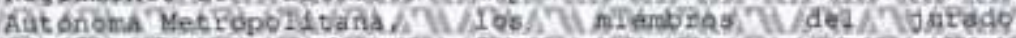
rasolvistom?

\section{APROBAR}

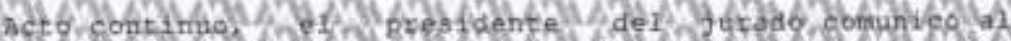

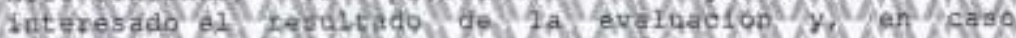

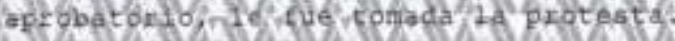
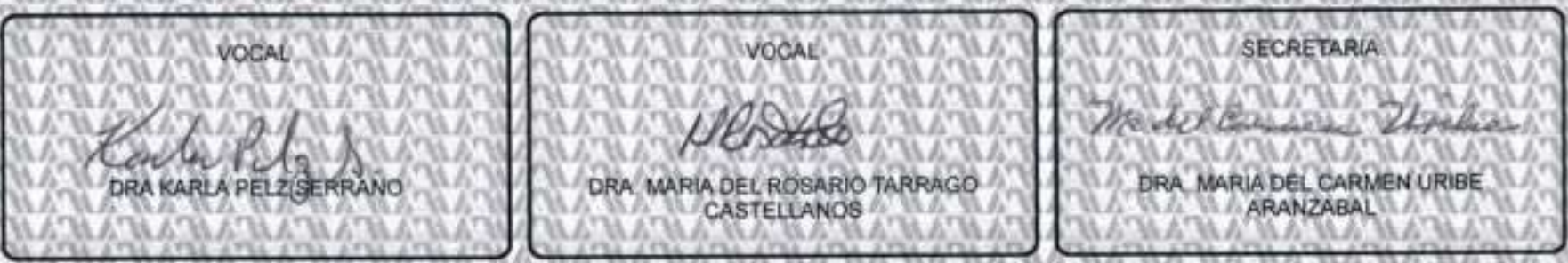